\title{
La cultura del horror \\ en las sociedades avanzadas: \\ de la sociedad centrípeta \\ a la sociedad centrífuga
}

\section{Eduardo Bericat Alastuey \\ Universidad de Sevilla \\ Centro de Estudios Andaluces \\ ebericat@us.es}

RESUMEN

El presente artículo expone los principales resultados de una investigación realizada con el objeto de analizar el papel que cumplen las emociones colectivas en el mantenimiento del orden social. En concreto, trata de explicar el hecho de que las noticias más importantes que aparecen en los medios de comunicación sean noticias de horror, es decir, noticias en las que la muerte siempre aparece en el primer plano de la escena. Los informativos de los medios de comunicación expresan y fomentan la cultura del horror característica de nuestras sociedades avanzadas. Ahora bien, para entender esta cultura es preciso determinar previamente la naturaleza emocional del horror, así como establecer una definición sociológica de este sentimiento. El horror es una emoción compleja compuesta por sentimientos de terror, de asco y de conmoción. El horror, sociológicamente, puede entenderse como «la emoción mediante la que un orden social señala sus límites más extremos». El estudio concluye señalando que existen dos modos alternativos de mantener el orden y la cohesión en el seno de un sistema social. El primer modo de legitimación, característico de las sociedades centrípetas, funciona mediante la gran potencia atractiva que ejerce sobre el campo social un núcleo central de valores sociales positivos. El segundo, característico de las sociedades centrífugas, funciona mediante la gran potencia repulsiva que ejercen sobre el campo social las transgresiones flagrantes del orden moral. El modo típico en el que las sociedades centrífugas regulan el orden social explica la cultura del horror característica de nuestras sociedades avanzadas.

Palabras clave: Sociología de la Emociones, Posmodernidad, Miedo, Horror, Terror, Asco, Conmoción, Climas Emocionales, Orden Social, Cohesión Social, Legitimidad, Cultura, Opinión Pública. 


\section{INTRODUCCIÓN}

En este artículo se presentan los resultados fundamentales de una investigación* que tenía por objeto mostrar y comprender la realidad de un cambio fundamental en la cultura de las sociedades avanzadas. Este cambio afecta específicamente a la estructura de nuestras emociones sociales, y se manifiesta en la existencia de un nuevo clima emocional. En concreto, sostenemos que las emociones colectivas de horror están jugando en la actualidad un papel clave en la constitución y en el mantenimiento del orden social característico de las sociedades posmodernas. De ahí que el estudio de la cultura del horror, omnipresente en el contenido informativo de las noticias que ofrecen los medios de comunicación, constituya un recurso heurístico de primer orden a la hora de comprender nuestra sociedad.

El cambio de clima emocional se percibe con suficiente claridad en el contenido de las noticias que aparecen en los medios de comunicación de masas, esto es, en la televisión, en la radio y en la prensa. Una buena parte de estas noticias nos ofrecen informaciones acerca de hechos luctuosos, de tragedias y dramas, de desastres e infortunios, de muerte y desolación. La muerte siempre está presente en las noticias más importantes, bien sea una muerte expuesta directa y crudamente en su apariencia más sanguinaria, en la que el cuerpo mutilado y el cadáver ocupan el centro de la escena, bien sea una muerte anunciada y sugerida como acontecimiento probable y generalizado, consecuencia de fenómenos, hechos o comportamientos considerados en gran medida normales.

Una secuencia informativa compuesta de muertes, o, en su defecto, de riesgos de muerte, parece ser el contenido común del bloque más importante de los informativos. El gran desastre causado por un huracán o por una tormenta tropical; un accidente aéreo, de metro o de ferrocarril; la sangría de los accidentes de carretera; la violencia criminal ejercida por los varones sobre las mujeres; la infernal desolación de los actos terroristas; los riesgos para la salud derivados del consumo de tabaco, alcohol y drogas; la conducta de perros peligrosos que atacan a las víctimas más débiles e indefensas; cadenas alimentarias que transmiten enfermedades animales a los humanos; epidemias de virus o bacterias desconocidas hasta ahora que se difunden globalmente a la velocidad del sonido; médicos o enfermeras que matan a sus enfermos; canguros que maltratan a los bebés que deberían cuidar; prácticas biotecnológicas de científicos que pueden estar irresponsablemente jugando a ser dios; escapes nucleares; vertidos petrolíferos letales; guerras y más guerras; limpiezas étnicas y genocidios; crímenes raciales; crímenes espantosos y violencia sin sentido.

\footnotetext{
* La investigación, titulada «El rol de las emociones colectivas en la constitución y el mantenimiento del orden social», se realizó con una ayuda del Ministerio de Educación, Cultura y Deporte, del Programa de Movilidad para Estancias de Profesores en Centros Extranjeros, como Visiting Researcher en el Departamento de Sociología de la Universidad de California, Santa Bárbara (UCSB), y bajo el auspicio del profesor Thomas Scheff.
} 
Todas estas noticias nos «informan» sobre diversos acontecimientos, pero todas ellas proyectan sobre la sociedad una misma e idéntica emoción, la emoción del horror. No importa cuál sea el acontecimiento ni dónde se haya producido. Es como si el destino último y exclusivo de las noticias fuera conformar un estado emocional, esto es, inyectar tanto en la comunicación pública como en la conciencia individual un flujo regular de hechos espeluznantes que alimenten los sentimientos colectivos del horror. Desde los presupuestos de la moderna teoría de la información, la prensa y los noticiarios debían cumplir exclusivamente un estricto papel de mediadores informativos, es decir, debían limitarse a transmitir al ciudadano, de forma tan neutral y objetiva como fuera posible, informaciones puramente cognitivas. Según Habermas, también debían constituir el espacio natural de un diálogo perfecto, libre, racional y razonable, que conformara la opinión pública en el marco de múltiples debates sociales. Sin embargo, muy lejos de lo previsto por estos modelos ideales, actualmente podemos percibir un cambio en la funcionalidad básica de estos informativos.

Los informativos de los medios de comunicación, antes que formadores de la opinión pública, aparecen hoy como creadores de emociones públicas. La teoría de la información, así como la teoría de la opinión pública, consideraba el contenido de los noticiarios en términos puramente cognitivos. Sin embargo, hoy podemos comprobar que los medios no sólo transmiten informaciones cognitivas, sino que, fundamentalmente, proyectan sobre la población intensos estados emocionales (Bericat, 1999). La prensa, así como los noticiarios de la radio o de la televisión, se asemejan mucho más a rituales de duelo y de horror, con una altísima y a la vez siniestra carga emocional, que a un proceso de mera transmisión objetiva de informaciones, o a un ágora pública en la que los ciudadanos deciden razonando el destino de su comunidad.

Algunos investigadores sociales han constatado la abundante presencia del miedo en el contenido de los informativos, tratando al mismo tiempo de explicar o de comprender esta insospechada y extraña presencia. Libros como Culture of Fear. Risk-taking and the Morality of Low Expectation, de Frank Furedi (Furedi, 1997); The Culture of Fear. Why Americans Are Afraid of the Wrong Things, de Barry Glassner (Glassner, 1999); Creating Fear. News and the Construction of the Crisis, de David L. Altheide (Altheide, 2002); o El miedo es el mensaje. Riesgo, incertidumbre y medios de comunicación, de Enrique Gil Calvo (Gil Calvo, 2003), ponen de manifiesto el hecho de que los medios de comunicación están generando en nuestras sociedades un clima o cultura emocional de miedo. Ahora bien, todos estos autores se enfrentan a similares problemas y paradojas a la hora de comprender y/o explicar la omnipresencia de este sentimiento colectivo. ¿Cómo puede explicarse el hecho de que el miedo haya penetrado de una forma tan profunda en el cuerpo de sociedades hipermodernas, tecnológicamente avanzadas y poderosas, cuyo grado de control es incomparablemente mayor a cualquier otra sociedad precedente y conocida? 
Nuestra respuesta consiste en afirmar que la disolución de esta y otras paradojas exige una seria matización metodológica. Pese a la escasa importancia científica que actualmente se otorga a la descripción de los fenómenos sociales, debemos subrayar el hecho de que es imposible alcanzar una explicación válida partiendo de una descripción imprecisa, falsa o engañosa. En este sentido, mantenemos que el error de todos estos autores consiste en creer que existe una cultura del miedo. Han tomado como base descriptiva bien la frecuencia de uso del término, bien la frecuencia de noticias con ese contenido emocional. Nosotros creemos, sin embargo, que no es el miedo el sentimiento que caracteriza a nuestra cultura emocional, sino las emociones colectivas de horror sentidas ante la visión de determinados acontecimientos especialmente trágicos, inhumanos, espeluznantes, brutales, crueles o monstruosos. Estos acontecimientos, pese a ser más infrecuentes o raros, son los que otorgan sentido a la mayoría de los miedos que aparecen en los medios de comunicación. En el origen de la atención pública prestada a todos estos miedos siempre podemos encontrar uno o varios acontecimientos horrorosos que han obtenido una fabulosa notoriedad pública. El acontecimiento horroroso es, desde nuestra perspectiva, el fenómeno generatriz y constituyente de estos miedos que parecen caracterizar a las sociedades avanzadas. De ahí que, para comprender esta cultura del miedo, debamos explicar y comprender la resonancia social que obtienen estos acontecimientos de horror. El verdadero estado emocional de nuestras sociedades, como iremos viendo a lo largo de este artículo, no puede entenderse como una simple cultura del miedo, sino como una compleja cultura del horror.

Entre las paradojas que surgen a la hora de explicar la cultura del miedo se encuentra la señalada por Glasser, quien no comprende por qué se dedica una ingente cantidad de recursos informativos a hechos, sin duda trágicos pero altamente improbables, que afectan tan sólo a una ínfima parte de la población. Por qué las sociedades elaboran y difunden una ingente cantidad de información sobre casos muy excepcionales de matanzas que se producen en los institutos norteamericanos, por ejemplo el caso de la matanza de Columbine, y tan poca sobre riesgos reales, probables y extendidos, como pueden ser las muertes debidas a enfermedades coronarias, o los problemas derivados de la vivienda, la educación, el desempleo o la calidad de vida. Glasser sostiene, por tanto, que los medios de comunicación nos atemorizan con miedos irreales, y omiten información sobre los asuntos que más le interesan a la mayoría de las personas. El problema de la tesis de Glasser, como veremos, es que los acontecimientos a los que se refiere no son de miedo, sino típicos acontecimientos de horror.

La perspectiva de Altheide se basa en señalar a los intereses de los medios de comunicación, así como a los intereses políticos que sustentan estos medios, como el principal factor explicativo de esta cultura del miedo. El propio título, Creating Fear, anuncia la tesis de 
la producción artificial del miedo, motivada por la necesidad que tienen los medios de captar la atención pública en un mercado muy competitivo. Los índices de audiencia y los beneficios siguen cursos paralelos. Sin embargo, este argumento es circular y bastante débil, pues en ningún caso se alcanzarían los ansiados índices de audiencia si no existiera una previa predisposición social al miedo. Los medios no serían capaces de proyectar miedo si, utilizando la terminología de Luhmann, el miedo no gozara de una cierta resonancia social. Pero en este punto topamos con una nueva paradoja, señalada por el propio Altheide: los mismos ciudadanos que hoy viven durante más años, con estilos de vida más seguros y confortables que los de ningún otro tiempo de nuestra historia, son también los mismos que expresan el mayor miedo e incertidumbre ante la vida.

Es un hecho que ninguno de los autores citados dedica una sola página a clarificar la naturaleza de la emoción que constituye el objeto de su estudio, esto es, el miedo. Toman la descripción de sentido común que utilizan los propios medios como una descripción real, como un concepto que ofrece suficientes garantías de contar con la necesaria validez científica. Y no es así. El universo emocional con el que nos comunicamos los seres humanos es demasiado complejo y sutil como para comprender su verdadera naturaleza utilizando una paleta de seis colores. Si bien es cierto que la sociología de las emociones constituye una subdisciplina muy reciente, no por ello estamos eximidos de la responsabilidad científica de utilizar conceptos válidos, máxime cuando abordamos el amplísimo universo de las emociones humanas. Nuestra hipótesis sostiene que la mayor parte de las paradojas explicativas se disuelven cuando entendemos que el clima emocional característico de nuestras sociedades corresponde a una cultura del horror.

En el epígrafe siguiente aportaremos pruebas empíricas de la existencia de esta cultura del horror. En el epígrafe tercero ofrecemos una descripción válida del objeto de estudio, lo que nos ha llevado a determinar con precisión tanto la naturaleza emocional como el contenido socio-relacional de los sentimientos de horror. Clarificada conceptualmente esta realidad emocional y relacional, avanzaremos un paso más aportando una definición o teoría sociológica del horror. Armados con este bagaje, en el epígrafe quinto expondremos nuestra tesis acerca de la conexión existente entre la cultura del horror y el proceso de cambio de época que nos está llevando desde la modernidad hasta la posmodernidad. Esta transformación implica un cambio radical en el modo de legitimación de nuestro orden social, que deja de ser el típico de una sociedad centrípeta, como la sociedad moderna, y pasa a ser el de una sociedad centrífuga, como lo es la sociedad posmoderna. 


\section{EL HORROR EN LA CULTURA Y EN LOS MEDIOS DE COMUNICACIÓN}

Antes de abordar las tareas mencionadas era preciso disponer de alguna información empírica que confirmara nuestras primeras impresiones, es decir, la percepción de que los informativos se estaban poblando de acontecimientos horrorosos. Para ello utilizamos una base de datos textual que incluye todos los artículos publicados en The New York Times desde el día de su aparición hasta la actualidad. Con la ayuda de esta base se han calculado, para un período de 140 años, el número de artículos de prensa en cuyo contenido emocional aparecía el término horror o alguno de sus derivados. Pues bien, tal y como puede apreciarse en el gráfico, el número de este tipo de artículos no ha dejado de crecer desde mediados de la década de los sesenta hasta la actualidad. El crecimiento se produce en términos absolutos, pero también en términos relativos. El número de artículos con contenido de horror, por cada mil publicados en el año, se cuadruplica en las tres últimas décadas del siglo xx. El índice parte del valor 5 en el año 1970, llegando a alcanzar el valor 20 en el año 2000. En suma, esta evidencia empírica constata la sensación de que los telediarios, los noticiarios radiofónicos e incluso la prensa escrita calificada de seria han incrementado su información sobre acontecimientos horrorosos, espeluznantes, bárbaros, crueles o inhumanos. Acontecimientos que provocan un gran impacto emocional y atraen la atención de miles y miles de personas en torno a un común sentimiento de estupor.

Horror en The New York Times, 1860-2000

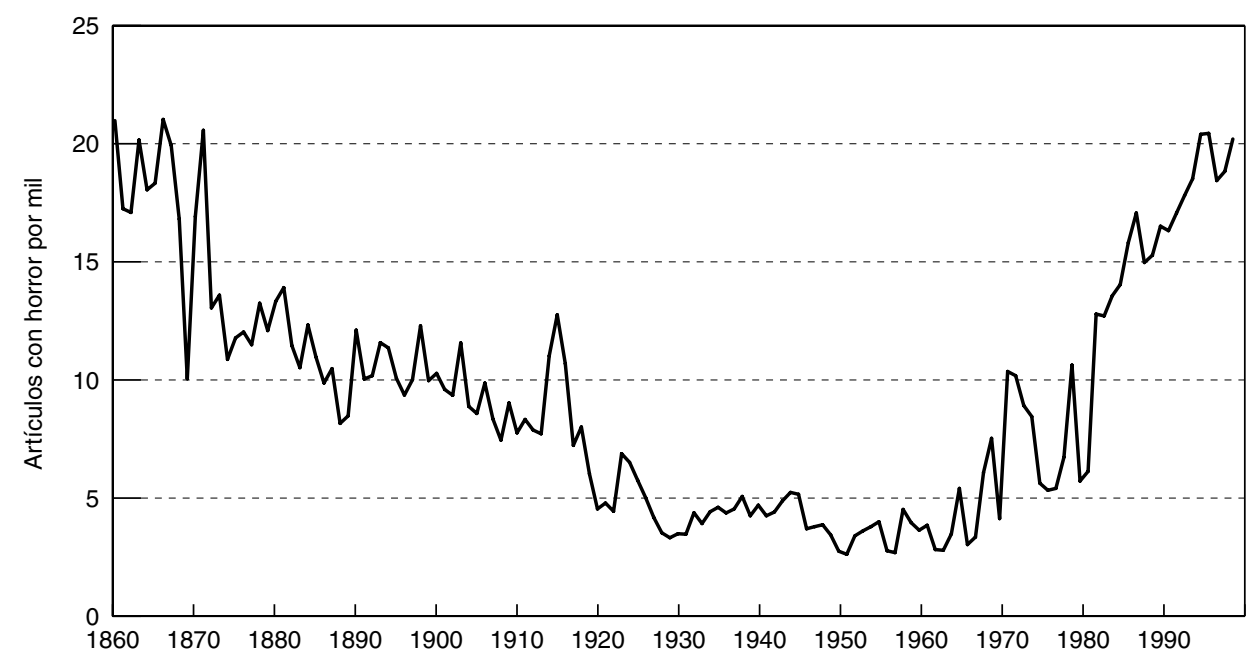

Tasa: Número anual de artículos con contenido de horror por cada mil artículos publicados en el año.

FUENTE:

Base de datos textuales PROQUEST. Elaboración propia. 
En el gráfico podemos observar que el número de artículos con horror es muy alto en la década de 1860, aunque ya en 1875 se registra un descenso considerable. Desde 1875 se inicia una clara tendencia descendente, ligera pero duradera y continua, que llevará finalmente el índice de horror hasta los mínimos históricos alcanzados en 1920. Es de resaltar, sin embargo, el significativo incremento del índice en torno a 1915. A partir de 1920, y durante medio siglo, esto es, hasta 1970, el índice de horror se mantiene en los niveles mínimos alcanzados ya en la década de los veinte, siendo en todo caso inferior al cinco por mil, si exceptuamos el ligerísimo aunque también significativo incremento del año 1945. Podemos considerar 1965 como el año en el que se inicia un importante cambio de tendencia en el índice de horror. Al principio este cambio muestra considerables altibajos, pero ningún dato pone en cuestión la sólida tendencia ascendente que muestra el índice de horror durante las tres últimas décadas del siglo xx. Al terminar el siglo el índice vuelve a alcanzar máximos históricos que superan el veinte por mil. A la luz de estos datos, por tanto, se corrobora la impresión generalizada de que en los últimos años hemos asistido a un sistemático y sustancial incremento de las noticias con horror en los informativos de los medios de comunicación.

Exceptuando el alto índice de contenido de horror de la década de 1860, década en la que aparece The New York Times, el gráfico presenta dos grandes fenómenos históricos dignos de atención. En primer lugar, los bajos índices de horror que se mantienen a lo largo de cincuenta años en la parte central del siglo xx, es decir, desde 1920 hasta 1970. En segundo lugar, el continuo incremento de este índice durante las cuatro décadas siguientes. Los bajos índices de la parte central del siglo pasado podrían interpretarse como la expresión de una conciencia satisfecha, conciencia de una sociedad moderna, ya avanzada, capaz por fin de disfrutar de muchos de los logros sociales, políticos, culturales y económicos con los que había soñado desde sus mismos orígenes. Conciencia expresada sociológicamente de forma paradigmática en la obra de Talcott Parsons. En El sistema social (Parsons, 1982), obra publicada en 1951, se concibe la sociedad como un organismo funcional regulado por un cuerpo central de valores aceptados universalmente y que mantiene estables los parámetros de su funcionamiento básico. Constituye la conciencia satisfecha de una sociedad que cree y siente haber alcanzado su destino, en el que sus anhelos más íntimos coinciden con el orden social presente, y que no desea otra evolución que el mantenimiento homeostático de ese orden social.

Esta conciencia satisfecha perduraría hasta bien entrada la década de los sesenta, en la que comienzan a aparecer los primeros síntomas de insatisfacción y los primeros movimientos sociales de contestación. La revolución de Mayo del 68, el movimiento hippy y, en general, la llamada contracultura expresarían la potencial insatisfacción contenida en el seno de una sociedad satisfecha (Roszak, 1981). No es extraño que fueran los jóvenes 
quienes, ajenos a pretéritas ilusiones y criados en una sociedad de la abundancia, en una sociedad democrática y libre, pero racionalista, materialista e individualista, reclamaran otros valores y formas de vida para sus propios proyectos vitales. Estos nuevos valores y formas de vida negaban, de hecho, los valores centrales que habían alimentado los desvelos y sufrimientos de la sociedad moderna. Para escándalo de los padres, los jóvenes parecían decirles: habéis llegado hasta aquí y os sentís legítimamente orgullosos por ello; pese a todo, no encontramos sentido ni al panorama ni al horizonte que habéis trazado para nuestras vidas.

Ahora bien, el hecho que supuso una ruptura verdadera, una ruptura radical de la conciencia satisfecha de la modernidad, tanto para los padres como para los hijos, se había producido algunos años antes. La Segunda Guerra Mundial trajo consigo el horror de todos los horrores, la indiscriminada y masiva matanza de judíos, los campos de concentración, los hornos crematorios, la inhumanidad más absoluta, la crueldad despiadada, la voluntad de poder sin límites y, por supuesto, la guerra. La presencia ineluctable de las fuerzas del mal, del Mal con mayúsculas, en el seno de uno de los países más desarrollados y civilizados del planeta, Alemania, alteró profundamente la conciencia satisfecha de la modernidad y de la civilización occidental. El ingenuo sentimiento de confianza expresado originalmente en la obra positivista de Comte se transmutó en un profundo sentimiento de desconfianza e incertidumbre. El ingenuo de Voltaire sería, a partir de Auschwitz, el confiado en las bondades puras de la modernidad y de la llustración, el crédulo incapaz de imaginar que la racionalidad instrumental y el poder tecnológico pudieran traernos algún peligro reseñable.

Los efectos que sobre la conciencia social tuvo el gran horror provocado por la Segunda Guerra Mundial, como puede comprobarse en el gráfico, no fueron inmediatos. La conciencia satisfecha pervivió incólume durante al menos dos décadas más. Solamente la filosofía (Bernstein, 2002) y el arte (Bozal, 2004), expresiones de la conciencia más sensible, detectaron desde el primer momento el cambio de rumbo. Partiendo de la traumática experiencia de la Segunda Guerra Mundial, M. Horkheimer y T. Adorno iniciaron una crítica de la era moderna basada en la imposibilidad de pensar positivamente el mundo. Su convencimiento más íntimo se nutría de la incapacidad para describir o determinar lo Bueno o lo Absoluto, tal como pusieron de relieve, ya en 1947, con la publicación de su Dialéctica de la Ilustración. M. Horkheimer, en su Crítica de la razón instrumental (Horkheimer, 1973), alertó sobre el vacío moral al que conduciría el olvido y el desprecio de la razón sustantiva. T. Adorno, con la publicación en 1951 de Mínima moralia (Adorno, 2004), renegaba de todo paradigma moral absoluto y totalizante. Con la publicación de Dialéctica negativa (Adorno, 1975), mostró que el pensamiento crítico sólo podía partir del análisis de las negatividades del mundo. 
La ingenua confianza y seguridad en el desenvolvimiento exclusivamente positivo del proyecto moderno dio paso a la desconfianza y a la incertidumbre sobre el futuro. La eliminación del sufrimiento, la barbarie y el horror es lo único que nos puede unir a todos en una voluntad renovada por la transformación social. Si el Bien absoluto no existe ni podemos determinarlo, vigilemos entonces los padecimientos humanos, miremos de frente las múltiples y atroces posibilidades del mal. Como ya hemos afirmado, sólo muy lentamente tanto la cultura de las sociedades avanzadas como su opinión pública han ido tomando clara conciencia de la negatividad, siguiendo los pasos de los pensadores y artistas más sensibles. La sociedad moderna orientaba positivamente su mirada hacia el futuro esforzándose en la consecución de sus grandes valores y en el logro de bienes incuestionables. Las sociedades posmodernas cambian su percepción del mundo, orientando negativamente su mirada hacia el futuro con el íntimo propósito de evitar los grandes males que les acechan. Creemos que este cambio radical de la conciencia moderna es el que se expresa en la hegemonía que los acontecimientos de horror tienen en la cultura y en la opinión pública de las sociedades posmodernas.

Dado que, por razones de espacio, no aportamos más datos empíricos que los incluidos en el gráfico, podría pensarse que esta tendencia es exclusiva del periódico The New York Times. Ahora bien, utilizando la base de datos textuales LEXIS NEXIS, que incluye información de más de cien periódicos, desde 1980 hasta la actualidad, hemos comprobado que el incremento de noticias de horror en las últimas décadas del siglo xx constituye un fenómeno generalizado tanto en la prensa de Estados Unidos como en la de Gran Bretaña. The Financial Times, USA Today, The Washington Post, The Guardian y otro amplio conjunto de periódicos registran en mayor o menor medida idéntica tendencia. Además, es preciso tener en cuenta dos importantes consideraciones. Primero, que esta prueba empírica se ha realizado «en el caso más desfavorable», es decir, en la prensa escrita calificada de seria, la que teóricamente debería estar menos dispuesta a incluir intensos contenidos emocionales. No ha de extrañarnos, por tanto, el fabuloso incremento de los contenidos emocionales en otros informativos y formatos de los medios de comunicación. Segundo, que un índice de horror del veinte por mil ha de considerarse muy alto, a tenor del inmenso despliegue y seguimiento informativo que, como hemos comprobado empíricamente, suele acompañar a cada una de estas noticias. La cantidad de informaciones publicadas sobre estos acontecimientos horrorosos en los que no se incluye la palabra horror, ni ninguno de sus derivados, es abrumadora. Piénsese, por ejemplo, en la cobertura informativa del hundimiento del Prestige, en el global despliegue informativo de la matanza de Columbine, en la cobertura otorgada en Estados Unidos a la pederastia de los curas católicos o a la del ídolo musical Michael Jackson, o en la que dedican los medios españoles durante los últimos años al maltrato femenino o a la violencia de género. Como hemos comentado, en el origen de estas inmensas coberturas mediáticas siempre encontramos un constituyente acontecimiento de horror. 


\section{LA NATURALEZA EMOCIONAL Y SOCIO-RELACIONAL DEL HORROR}

Hemos sostenido que el cambio de clima emocional de las sociedades avanzadas no puede interpretarse como la mera introducción de una cultura del miedo. El miedo es una emoción puramente instrumental propia de aquellas situaciones en las que el agente se enfrenta a un poder superior y anticipa potenciales consecuencias negativas para él. Desde esta perspectiva del miedo no se entendería en ningún caso el hecho de que la civilización moderna, caracterizada por el ininterrumpido desarrollo de sus capacidades de control sobre el mundo natural, social y personal, así como por haber elevado exponencialmente su potencia, hubiera alcanzado un estado final de miedo endémico y omnipresente. ¿Cómo entender este resultado emocional desde el orgullo característico de la civilización moderna? ¿Cómo entender, en suma, que los individuos de las sociedades avanzadas, esto es, las sociedades más poderosas y seguras, las sociedades de la abundancia, las sociedades más libres y con mayor capacidad para reducir todo tipo de contingencias, vivan atenazados por un miedo inexplicable, vergonzoso y casi infantil? Norbert Elias añade a este absurdo una nueva paradoja: en las sociedades donde la presencia de la muerte constituye un hecho cotidiano, las gentes han de aprender a vivir y viven sin miedo, pues de lo contrario la vida sería insoportable e impensable (Elias, 1993). Sin embargo, en las sociedades avanzadas, en las que el horizonte de la muerte aparece más lejano e improbable, la gente parece enfrentarse temerosa y temblorosa a cualquier contingencia vital.

Debido en parte a resultados obtenidos en investigaciones precedentes (Bericat, 1999 y 2002), y en parte a intuiciones derivadas de una observación asistemática del contenido de los informativos actuales, formulamos la hipótesis de que el horror, y no el miedo, era el verdadero sentimiento constitutivo de las sociedades avanzadas. Siguiendo las directrices de la obra de Wittgenstein, decidimos acometer un análisis minucioso, casi microscópico, de los usos socio-lingüísticos del horror tal y como aparecían en el contenido de los informativos de los medios de comunicación. Para ello, utilizando de nuevo la base de datos textuales LEXIS NEXIS, extrajimos una muestra representativa de los artículos con contenido de horror publicados en cinco periódicos norteamericanos desde 1990 hasta 2002. Mediante el análisis de sus usos socio-lingüísticos, determinamos tanto la naturaleza emocional como la naturaleza socio-relacional de los sentimientos colectivos de horror.

El horror constituye una emoción compleja compuesta por la síntesis de tres emociones muy intensas, a saber, el terror, el asco y la conmoción. El terror forma parte de la familia emocional del miedo; el asco forma parte de la familia emocional de la vergüenza; y la conmoción forma parte de la familia emocional de la sorpresa. El sentimiento de horror comporta siempre un intenso miedo o terror, pues revela la presencia de una fuerza muy poderosa capaz de causar en el sujeto un inmenso mal. Al mismo tiempo, el acontecimiento 
horroroso nos provoca una profunda repugnancia o asco, una potente revulsión de las vísceras con la que el cuerpo expresa la voluntad de rechazar absolutamente algo moralmente detestable e intolerable que ha penetrado en su interior. Por último, el acontecimiento horroroso nunca llega como un suceso normal o cotidiano, sino como ruptura radical de la normalidad, como una sorpresa tan completa e inimaginable que nos deja absolutamente perplejos en un estado de fuerte shock o conmoción.

Algunos ejemplos paradigmáticos, como el atentado de las Torres Gemelas del 11 de septiembre, los atentados del 11 de marzo en Madrid, la aparición de la enfermedad del SIDA en los años ochenta, los casos brutales de maltrato femenino, los crímenes y delitos sexuales cometidos contra los niños, o el mismo Holocausto judío, que constituye el paradigma socio-histórico del horror, pueden servirnos para entender esta específica síntesis emocional. En el atentado de las Torres Gemelas observamos las consecuencias de un poder, hasta entonces oculto, pero capaz de sacudir el corazón del imperio dejando a su paso muerte y desolación. Podemos observar la honda repugnancia evocada por el atentado en el cuerpo de la nación americana, así como todos los esfuerzos subsiguientes realizados para expulsar de su interior, así como para evitar futuras intromisiones, de ese elemento extraño que amenaza su supervivencia social. También se manifiesta en este ejemplo la inmensa sorpresa característica del horror, el estado de shock producido por un hecho absolutamente impensable, inconcebible e inimaginable. Ésta es en esencia la fenomenología emocional que aparece en toda situación horrorosa, sea la correspondiente a un gran horror colectivo, sean las diversas y múltiples situaciones cotidianas de horror que tenemos que sufrir en nuestras vidas. Puede variar la intensidad, pero permanece constante una idéntica composición emocional.

El enorme interés sociológico de los sentimientos de horror comenzó a vislumbrarse cuando, siguiendo los planteamientos teóricos del profesor Th. K. Kemper (Kemper, 1978), pudimos determinar la naturaleza socio-relacional de cada uno de sus tres componentes emocionales. En el estudio cualitativo de los casos de horror se prestó especial atención al análisis de la situación social y de la estructura relacional implícita prototípicamente en todos los acontecimientos horrorosos. De este modo, se puso de manifiesto que el miedo y el terror están siempre vinculados a la dimensión de poder implícita en toda relación social, es decir, a lo que los seres humanos podemos hacernos los unos a los otros (interactividad). Por su parte, los sentimientos de asco y repulsión revelaron el vínculo que mantienen con la dimensión moral presente en todas nuestras relaciones sociales, es decir, con todo aquello que los seres humanos podemos decirnos los unos a los otros (intercomunicación). En último término, la conmoción derivada de la sorpresa parecía detectar siempre la existencia de una determinada ruptura del orden social, de esa realidad o mundo cerrado y naturalizado que tiende a crear toda unidad social (orden/caos). 
Las tres emociones inmanentes a todo horror corresponden al polo emocional negativo asociado con cada una de las tres dimensiones citadas de la interacción social. En el ámbito interactivo, el terror corresponde a una situación de suma impotencia frente a una fuerza que tiene tanto la pretensión como la capacidad de aniquilar al sujeto. En el ámbito intercomunicativo, el asco y la repugnancia corresponden a un estado simbólico de absoluta falta de consenso, en la que el sujeto expone de la forma más radical y corpórea posible el rechazo moral de una determinada conducta. En el ámbito del orden/caos social, el shock de la conmoción indica una ruptura flagrante y sorpresiva del orden social de la interacción. En suma, el horror expresa emocionalmente la más absoluta y pura negatividad.

ESQUEMA 1

Componentes emocionales y socio-relacionales del horror

\begin{tabular}{rrr} 
Emoción & Familia emocional & Dimensión social \\
\hline Terror & Miedo & Interactividad \\
Asco & Vergüenza & Intercomunicación \\
Conmoción & Sorpresa & Orden/caos
\end{tabular}

\subsection{El terror}

En la teoría socio-relacional de Kemper (Kemper, 1978), el grado de poder con el que cuenta el sujeto en relación al otro da lugar a un conjunto específico de diferentes emociones. Entiende que el sentimiento de culpa es típico de una situación en la que el sujeto dispone de, o ejerce sobre el otro, un poder excesivo. El sentimiento de seguridad aparece en aquellos contextos estructurales en los que el agente cuenta, o cree contar, con un nivel de poder adecuado. Por último, cuando el sujeto tiene, o cree tener, frente al otro un insuficiente grado de poder, entonces afloran sentimientos de miedo o de ansiedad. Y si para Weber el poder «significa la probabilidad de imponer la propia voluntad, dentro de una relación social, aún contra toda resistencia y cualquiera que sea el fundamento de esa probabilidad» (Weber, 1979: 43), entonces deberemos concluir que el miedo se constituye en una pura relación instrumental. El sujeto, en un contexto de escaso poder, se enfrenta a fuerzas del entorno, sea natural o social, cuya actividad implica, siguiendo a Hume (Hume, 1981), la probabilidad de un perjuicio o de un daño. De ahí que la respuesta prototípica del miedo sea la huida, que aleja al sujeto del ámbito de influencia de la fuerza que le amenaza, o la lucha, mediante la que se pretende usar recursos de poder escasos para obtener una victoria improbable. 
Según Kövecses, autor de un interesante estudio en el que analiza las metáforas lingüísticas que utilizamos para aludir a diferentes emociones, el terror aparece como un miedo caracterizado por unos síntomas fisiológicos y por unas respuestas conductuales mucho más intensas. Los pelos de punta, la caída de la temperatura corporal, la imposibilidad de moverse y de respirar, así como la incapacidad para hablar o para pensar, forman parte de la fenomenología del terror. Pero el terror no sólo se distingue del miedo por su intensidad. El estado emocional de terror implica, además, una situación de falta absoluta de control frente a un peligro inminente que amenaza la supervivencia del sujeto (Kövecses, 1990: 79). En suma, el terror es una emoción que señala el riesgo inminente e ineluctable de un enorme daño, prototípicamente la muerte, en el contexto de una relación de poder o de fuerzas muy desfavorable, en la que un sujeto impotente carece de la capacidad para controlar la situación.

El terror constituye un componente tan esencial del horror, y tan obvio, que solemos usar ambos términos indistintamente. Sin embargo, conviene subrayar una primera e importante diferencia. Mientras que en el terror el origen de la amenaza es siempre exterior al sujeto, en el horror la causa del peligro hunde sus raíces en la propia naturaleza del sujeto paciente. Ello explica que en el terror el sujeto esté exento de toda responsabilidad por el daño sufrido, mientras que en el horror asoma siempre algún atisbo de responsabilidad propia. La diferencia es sutil pero trascendental, y no atañe tanto al hecho en sí como a la atribución de culpabilidad que implica el exceso de poder y la amenaza de aniquilación implícitos tanto en el terror como en el horror. En el terror causado por un acto «terrorista» o por un desastre «natural», tanto los individuos como la sociedad aparecen como meros sujetos pacientes de una letal y tremenda fuerza exterior. La pura inocencia del sujeto que sufre no se pone en cuestión. En el horror, sin embargo, siempre emerge alguna imputación de responsabilidad propia. Cuando unos jóvenes asesinan a otros en un colegio, cuando algunos hombres maltratan cruelmente a sus mujeres, o cuando algunos policías torturan brutalmente a un detenido, centramos nuestra atención en la culpabilidad social: ¿En qué tipo de sociedad estamos viviendo? ¿Qué debemos cambiar en la sociedad para que estos hechos no vuelvan a producirse? ¿Quién o quiénes han permitido que esto sucediera? ¿Qué ha fallado para que un ser humano como nosotros haya llegado a cometer semejante atrocidad? El intenso terror implícito en el horror procede siempre del profundo miedo que sentimos frente al tremendo poder de autodestrucción que llevamos dentro.

En este sentido, la obra de Hobbes Leviathan resulta paradigmática (Hobbes, 1994). Su punto de partida es que todos los seres humanos estamos igualmente capacitados para causar la muerte de otro ser humano, por lo que todos tenemos buenas razones para temer a nuestros semejantes. En el estado de naturaleza el hombre es un lobo para el hombre, y el escenario de una violencia anárquica ejercida por todos contra todos aparece 
como la posibilidad más probable. El riesgo de caos social es inminente, y el horror al caos funda la necesidad de un pacto o contrato social mediante el que los individuos, en ejercicio de su libertad, ceden su capacidad de dañar al otro a una institución social creada por ellos mismos. El Estado-Soberano monopoliza de ahora en adelante el ejercicio de la violencia física, ofreciendo seguridad y orden a cambio de libertad. El hombre mismo construye así un instrumento de poder omnímodo, un monstruo, Leviatán, al que se enfrenta en un estado de pura impotencia. En suma, la construcción del orden político se funda en el miedo al otro y en el horror al caos social, esto es, en el terror a la capacidad destructiva que alberga la propia naturaleza humana. Y sólo conseguimos erradicar ese miedo difuso sustituyéndolo por «un Terror nítidamente pronunciado, ejercido y ejecutado» (Trías, 2004: 49). De este miedo a nosotros mismos acaba emergiendo un nuevo horror, el Estado omnipotente y absoluto frente al cual el individuo pierde toda su libertad. Pero tanto el horror del Estado como el horror del caos social son la expresión o el resultado de una misma fuerza poderosa que yace oculta en nuestro interior.

\subsection{El asco}

El asco o repugnancia constituye una de las emociones más viscerales. Su sintomatología fisiológica es muy potente, y viene acompañada de fuertes reacciones que alteran nuestras vísceras. Su expresión conductual más característica es el vómito, esto es, un reflejo corporal cuyo objetivo primario es la expulsión de un elemento que ha penetrado en el interior de nuestro cuerpo. En su forma preventiva se expresa como una fortísima resistencia a que algo, considerado esencialmente impuro y peligroso, contamine nuestro cuerpo o nuestra identidad (Miller, 1997). El asco y la repugnancia están íntimamente asociados con dos actividades humanas clave, como son la alimentación y el sexo, dos actividades que mantienen una relación primordial con la supervivencia, sea del individuo, sea de la especie. Podríamos decir que el asco cumple una función de filtro corporal que establece una separación neta entre el interior y el exterior, entre lo potencialmente asimilable por el organismo y aquello que le resulta absolutamente detestable.

Desde esta visceralidad inicial, la emoción del asco, con su lógica de control de paso, se extiende simbólicamente a otro conjunto de fenómenos menos corporales. De ahí que el asco constituya una de las metáforas más radicales en las que se expresa nuestra moralidad (Miller, 1997). Sobre todo aquella moralidad orientada no tanto a la consecución del bien como a la evitación del mal. Asimismo, también se proyecta sobre la estructura social cuando determinados grupos en el seno de la sociedad producen repugnancia a otros grupos. En este último caso, el asco establece una frontera prácticamente impermeable con el objeto de mantener diferencias radicales entre la naturaleza de los miembros de un grupo y 
otro (Douglas, 2002). El hecho de que la repugnancia constituye una construcción social, filogenética y ontogenéticamente, ha sido demostrado con magistral perspicacia por Norbert Elias en su estudio sobre la historia de los modales (Elias, 1993). El proceso civilizatorio occidental ha discurrido en paralelo a un continuo incremento de los umbrales de repugnancia.

Mary Douglas, en su obra Purity and Danger, aun sin mencionar explícitamente el sentimiento de asco, elaboró una teoría de lo impuro, de lo poluto y contaminante, que está asociada a los mecanismos emocionales de la repugnancia. Para Douglas, la materia contaminante constituye una clase específica de suciedad o polvo, que define estructuralmente como «materia fuera de lugar». La suciedad es siempre y esencialmente «desorden», "ofensa al orden». Toda sociedad o comunidad se estructura a sí misma y estructura su entorno en base a un complejo sistema de categorías. Sin embargo, no toda la realidad puede catalogarse perfectamente en estos sistemas simbólicos, así que la suciedad, en el fondo, siempre representa «ambigüedad» o «anomalía». De ahí, por ejemplo, que los materiales viscosos que no son líquidos ni sólidos, las personas deformes que son humanas pero no lo parecen, o los excrementos que proceden del interior pero pertenecen al exterior, pueden estar «fuera de lugar» en un determinado sistema de categorías y, por tanto, pueden producir repugnancia o asco. Aunque la teoría de Mary Douglas se interpreta normalmente en términos del estructuralismo simbólico que le dio origen, una lectura completa de su obra, especialmente de los últimos capítulos, pone de manifiesto que el mecanismo de repulsión opera también como forma de mantener no sólo un orden cultural, sino también un orden social. Cada vez que una comunidad se enfrenta a una indefinición de sus límites (Erikson, 1968), o de su identidad, el asco y la repulsión comienzan a proyectarse sobre diversos tipos o grupos sociales, evitando la coalescencia social e intensificando las fronteras tanto interiores como exteriores de la propia comunidad.

En suma, la obra de Douglas nos ofrece una adecuada interpretación socio-relacional de los sentimientos de asco, repugnancia, aborrecimiento y aversión visceral. En la lógica del asco siempre está implicada la creación o el mantenimiento de un límite o frontera, sea cultural o social, que distingue entre lo puro y lo impuro. El componente de asco que incluye el horror hace que este sentimiento sirva también para determinar límites y fronteras vinculados esencialmente al estado del orden social. Dado que el asco está en el horror combinado con un diferencial absoluto de poder, así como con el riesgo de aniquilación física o simbólica provocada por un elemento contaminante, la repulsión asociada a él representa el esfuerzo por eliminar del propio orden social aquello capaz de causar el máximo daño. Significa el esfuerzo por expulsar los hechos más abyectos que ponen en riesgo el orden social. Implica señalar de la forma más intensa posible lo más bajo y deleznable, lo que man- 
cha con el más profundo estigma de la vergüenza la identidad social de una determinada comunidad. En el horror, el componente de asco señala aquello que resulta moralmente intolerable y aberrante. Por tanto, no sólo distingue, como la vergüenza, lo correcto de lo incorrecto, o incluso lo bueno de lo malo, sino que establece una frontera impermeable y absoluta entre el Bien y el Mal. El asco del horror señala aquello que es considerado profundamente inmoral, malévolo y demoníaco. Señala la absoluta depravación que yace en nuestro interior.

\subsection{La conmoción de la sorpresa}

La conmoción o shock que llega de la mano del horror constituye, sin duda, una sorpresa en extremo desagradable y brutal, un fuerte e inesperado «golpe», como suele decirse en español, que recibe el individuo o la sociedad ante el horror. Pero constituye, ante todo, una extrema sorpresa, una ruptura total de las expectativas y una incapacidad absoluta para comprender el acontecimiento horroroso. En el shock de la sorpresa, que siempre comporta una paralización mental, los esquemas de pensamiento con los que solemos interpretar la realidad normal se muestran totalmente inservibles para atisbar siquiera una mínima explicación. ¿Por qué un padre de familia vuelve un día a casa pertrechado con una maza y mata a golpes a su mujer y a sus dos hijos? ¿Cómo podemos explicar la atroz matanza de tutsis llevada a cabo por los hutus? ¿Acaso podemos comprender el simple acto vandálico de unos jóvenes que nada obtienen de la destrucción del mobiliario público? El acto horroroso parece emerger repentinamente y sin ninguna explicación de la parte más oscura de la realidad humana, de ese abismo ignoto, incontrolable, que todo individuo y toda sociedad contiene en su interior.

El punto de partida para comprender el componente socio-relacional de la sorpresa es el concepto de orden social. Un orden social se configura como un «mundo» cerrado, controlado y regulado en cuyo interior queda reducida la contingencia (Luhmann, 1995). Existe orden en la interacción social cuando la conducta de los otros, pese a la doble contingencia que afecta a las relaciones sociales, se ajusta a mis expectativas, y viceversa. Este estado promueve la necesaria confianza para que los procesos de interacción social se desenvuelvan con suficiente fluidez. Asimismo, una determinada ecuación de control de las interacciones con la naturaleza fomenta el sentimiento de seguridad vital característico de cada orden. Finalmente, en un orden social las palabras se adecuan a las cosas, esto es, la realidad y su representación coinciden plenamente en el plano epistemológico de la verdad. El orden social instituye convencionalmente un mundo cerrado que, desde la perspectiva de los sujetos, tiende a naturalizarse. Entonces, el orden social aparece como un verdadero mundo u orden natural. 
Es evidente que todo orden social tiene que admitir en su seno un cierto grado de incumplimiento de las expectativas. Así, por ejemplo, si bien la conducta recíproca de unos amigos es altamente previsible, subsiste siempre la posibilidad de la traición, del mismo modo que subsiste la infidelidad en el seno de las parejas. Pero la sorpresa que provoca el conocimiento del traidor o del infiel constituye una sorpresa relativa, ya contemplada como posible en el seno del orden social. La sorpresa que acompaña al horror, sin embargo, no es sólo mucho más intensa, sino que está provocada por la aparición de un hecho totalmente inconcebible e inimaginable, un hecho absolutamente anormal que procede de un más allá de los límites del mundo.

Un análisis de contenido de algunas obras de la extensa literatura de horror nos ha mostrado que uno de los mecanismos que utilizan los autores para generar una atmósfera de horror es el uso de múltiples palabras precedidas por el radical negativo «in». Éste es el caso del clásico cuento de H. P. Lovecraft titulado The Dunwich Horror (Lovecraft, 2001). Acontecimientos increíbles, inconcebibles, inimaginables, incognoscibles, incomprensibles, inexplicables; hechos inexpresables, incomunicables, innombrables; realidades informes, incalculables, incomparables, innumerables, intangibles; y situaciones insanas, insufribles, intolerables e inhumanas. En el plano del contenido manifiesto, las realidades que sorpresiva y amenazadoramente penetran y aparecen en nuestro «mundo» pertenecen y provienen siempre de un absoluto exterior, monstruoso y radicalmente inhumano. El contenido latente, sin embargo, nos muestra que ese supuesto mundo exterior no es otro, según Freud, que el mundo de las sombras que yace en nuestro interior, esa inhumanidad reprimida y expulsada desde la que construimos el orden social.

Podemos comprender sociológicamente el tipo de sorpresa radical que adviene con el horror recordando los geniales «experimentos de ruptura» de Harold Garfinkel (Garfinkel, 1963). Estos experimentos fueron diseñados con el objeto de observar la reacción de los individuos ante violaciones de los supuestos normativos subyacentes al orden social. Dicho de otra manera, se trataba de investigar el funcionamiento del orden social provocando, precisamente, rupturas fundamentales de ese orden. Cuando propuso a sus estudiantes que al llegar a casa se comportaran ante su familia como perfectos desconocidos o extraños, rompiendo así las bases normativas de su habitual interacción, los familiares reaccionaron ante el hecho con infinita sorpresa, con estupefacción y con horror. El intolerable horror al vacío suscitó en un principio la búsqueda de explicaciones «normales». Tras el fracaso de esta búsqueda llegaron los primeros síntomas, apenas disimulados, de una intensa indignación. Finalmente, en los pocos casos en que los alumnos pudieron prolongar un poco más la representación de ese extraño rol, la situación se hizo insostenible y peligrosa. Los familiares aplicaron altas dosis de agresividad sobre el alumno con el único objeto de restituir, incluso por la fuerza, el orden normal de interacción. En suma, todo aquello que desde el exterior 
penetra en el interior de un orden social provoca siempre una tremenda conmoción, un fuerte shock producto de la absoluta perplejidad que llega con la sorpresa.

\section{LA DEFINICIÓN SOCIOLÓGICA DEL HORROR}

Según mostramos en el segundo epígrafe, los medios de comunicación nos informan cada vez más de acontecimientos horrorosos capaces de crear grandes conmociones colectivas. Es evidente, sin embargo, que no todos los individuos reaccionan de la misma forma ante las noticias. A algunas personas la noticia les puede provocar un auténtico e intenso horror, mientras que a otras, quizá a la mayoría, les evoque una ligera indignación o les sirva tan sólo para esbozar algunos comentarios casi intrascendentes en una simple conversación cotidiana. Es cierto, por ejemplo, que el atentado del 11 de marzo en Madrid conmocionó realmente a casi todos los madrileños y a muchísimos españoles. Es seguro que los neoyorquinos revivirían de algún modo, con el atentado de Madrid, el horror sufrido por ellos, pero desconocemos hasta qué punto afectó emocionalmente a japoneses o sudafricanos. A la inversa, los atentados con gas sarín cometidos en el metro de Tokio horrorizaron a los japoneses, aunque seguramente el resto del mundo sintió tan sólo una leve aunque sincera preocupación.

Desde la perspectiva de la sociología de las emociones, el hecho de que unos u otros individuos sientan en mayor o menor medida el impacto emocional de las noticias es hasta cierto punto irrelevante. Importa, desde luego, el impacto emocional realmente causado, pero importa sobre todo, aplicando el conocido teorema de Thomas, la «definición de la situación» con la que los medios transmiten las noticias. Las emociones públicas, más allá de las variaciones individuales que comporten, constituyen emociones de sociedad, y esto significa que el sujeto sentiente propio de estas emociones no es el individuo, sino la unidad social (Bericat, 2002a). En la medida que los medios de comunicación definan como horroroso un determinado acontecimiento o hecho, y los individuos acepten tal definición, simpatizando en cierto grado con ese estado emocional (Smith, 1997), podremos afirmar que se está proyectando horror sobre la conciencia colectiva o, dicho en términos más actuales, sobre la comunicación social. Por este motivo, definir sociológicamente el horror implica revelar la específica funcionalidad que pueda tener este sentimiento en la constitución, en el mantenimiento y en el cambio de un determinado orden social. Y desde esta perspectiva sociológica definimos el horror como la emoción mediante la que un orden social señala sus límites más extremos.

Esta definición contiene tres rasgos básicos que comentaremos en los párrafos siguientes. Primero, atribuye a este sentimiento una función de señal. Segundo, remite específicamente su funcionalidad al sujeto sentiente que les es propio, esto es, no al sujeto individual, sino 
a la unidad social. Y tercero, define el papel constitutivo de los sentimientos de horror como conciencia liminar que determina el límite externo más extremo de ese orden social, es decir, la frontera que separa lo pensable de lo impensable, lo tolerable de lo intolerable, lo humano de lo inhumano, y el Bien del absoluto Mal. En el interior del orden, como queda indicado en el esquema 2 , subsiste una multiplicidad de elementos que pueden ser catalogados de buenos o malos, de mejores o peores, de correctos o incorrectos, de convenientes o de inconvenientes. Pero el orden social sólo queda perfecta y nítidamente delimitado cuando establece las fronteras del MAL que le separan del caos o de la contingencia absoluta. Esta frontera define su identidad frente a todo aquello que pueda considerarse aborrecible, brutal, demoníaco, inhumano, bárbaro, malévolo y monstruoso. El horror es el abrupto sentimiento colectivo evocado en aquellas situaciones en las que las oscuras fuerzas del mal contenidas más allá de las murallas de la ciudad logran abrir una brecha y penetrar en su interior poniendo en riesgo su propia identidad y supervivencia.

ESQUEMA 2

Definición sociológica del horror: «El horror es la emoción mediante la que un orden social señala sus límites más extremos»

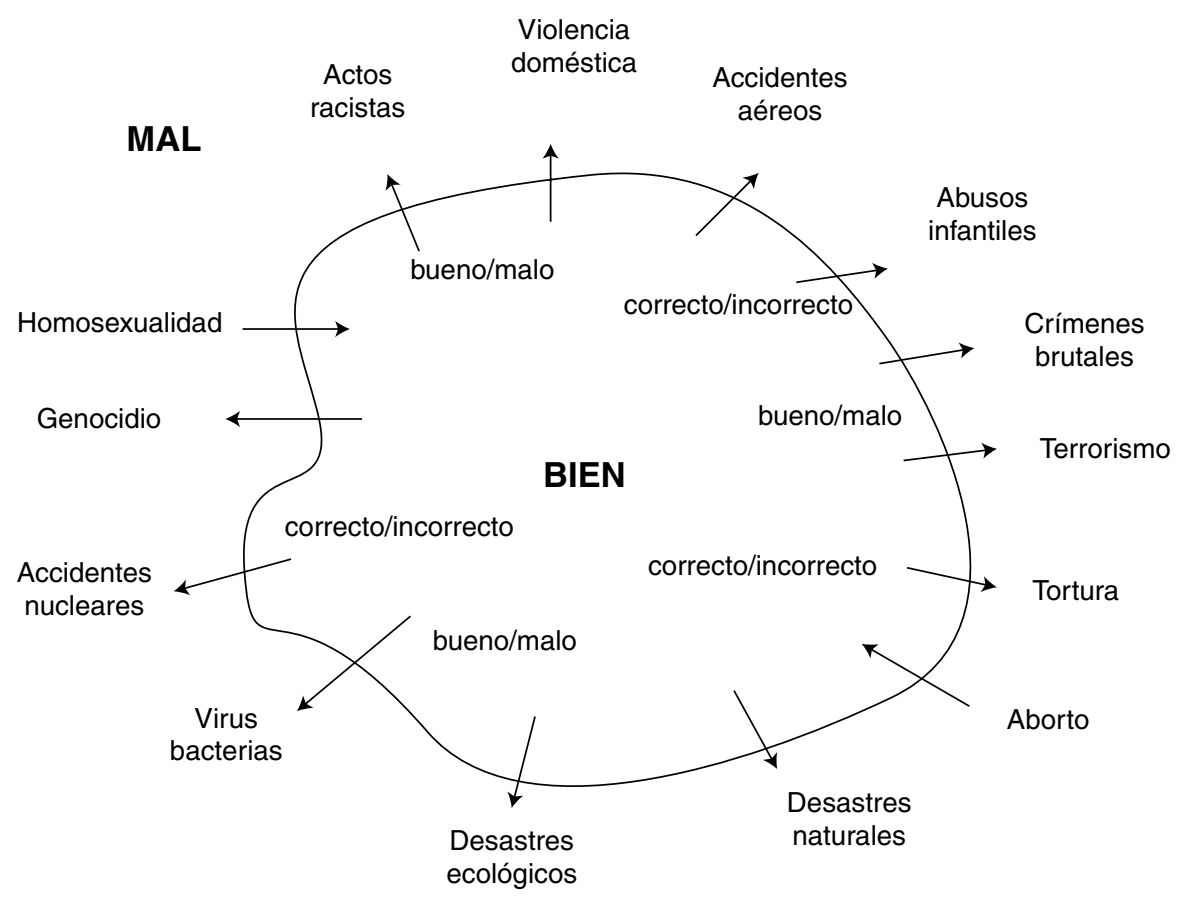


El hecho de que las emociones cumplen una función de señal fue inicialmente reconocido y desarrollado por Sigmund Freud en su trabajo «Inhibitions, Symptoms, and Anxiety» (Freud, 1926). La ansiedad constituye un indicador que alerta al yo de la existencia de algún peligro que procede del interior o del exterior. En su teoría de la vergüenza, también Thomas Scheff atribuye a los sentimientos una función de señal. Mientras que el orgullo pone de manifiesto la fortaleza del vínculo social que mantenemos con otra persona, la vergüenza revela siempre el deterioro del vínculo social existente entre dos sujetos. Así pues, la vergüenza y el orgullo constituyen un sensible giroscopio con el que las personas detectamos el estado de nuestros vínculos sociales (Scheff, 1991). Arlie R. Hochschild, investigadora a quien podemos considerar uno de los fundadores de la sociología de la emoción, generaliza esta idea al afirmar que las emociones señalan la relevancia que tiene una determinada situación para el propio sujeto (Hochschild, 1983: 28). Y la relevancia vinculada al sentimiento de horror es la que afecta a la principal diferencia que, según Luhmann, todo sistema social debe establecer, esto es, la que separa al propio sistema de su entorno.

En la teoría de Nicklas Luhmann el sistema se autoproduce distinguiendo sistema y entorno, pues el sistema implica un nivel de organización superior en el que se reduce la incertidumbre mediante el incremento de la complejidad sistémica (Luhmann, 1995). Todo orden social, sea el orden creado por una pareja, sea el de una sociedad global, implica determinados estados de clausura o cierre. En el interior de sus fronteras el «mundo» debe funcionar con arreglo a unos parámetros propios y distinguibles. Cada orden social, en tanto sistema de acción, estructura en su interior un tipo especial de operaciones diferentes tanto de las operaciones de su entorno como de las operaciones de otros sistemas u órdenes sociales. Los límites o fronteras sociales y simbólicos, tal y como se pone de manifiesto en el paradigma de Luhmann o en la obra del filósofo español Eugenio Trías, constituyen un mecanismo esencial tanto de la identidad como del mantenimiento de los sistemas sociales. Si bien es cierto que toda ordenación social subsiste merced a la existencia de un gran número de límites simbólicos y sociales (Lamont y Molnár, 2002), puede afirmarse que el horror constituye el límite por antonomasia, pues su función es establecer las fronteras más impermeables, la diferencia esencial entre mundos cuya mezcla corrompería la naturaleza de las cosas.

Los sentimientos de horror, según hemos señalado anteriormente, no distinguen entre lo bueno y lo malo, o entre lo correcto y lo incorrecto, que tan sólo constituyen meras posibilidades en el interior de un sistema, sino entre el Bien, es decir, entre todo aquello que es admisible y concebible, todo aquello que el sistema puede tolerar y regular, y el Mal, es decir, lo que resulta absolutamente inasimilable, intolerable y abyecto (Kristeva, 1982), las sombras que reinan en el exterior del orden social y que habitan en el oscuro mundo de la naturaleza humana.

Para comprender la radicalidad de esta oposición entre el Bien y el Mal hay que entender, como señala Martin Buber, que estos conceptos no aluden a dos estructuras de similar natu- 
raleza, aunque situadas en polos opuestos, sino que son dos cualidades cuya estructura difiere completamente (Buber, 1997: 64). Pese a lo dicho, es preciso señalar que el Bien y el Mal no se excluyen, pues el bien se construye domando la maldad, otorgando dirección a la pasión sin forma. Según Buber, la vida humana en tanto entidad específica, que ha emergido de la naturaleza, comienza con la experiencia del caos como una condición percibida en el alma (Buber, 1997: 125). Y esta misma idea es la que nos transmiten, según Paul Ricoeur, muchos mitos que narran la creación del mundo y de las divinidades que lo inspiran. El «mal primordial», que funda el caos y la indiferenciación originaria, precede al orden y participa en la constitución del orden. En el origen no existe ni Bien ni Mal, sino una monstruosa brutalidad, un absoluto desorden, un caos primordial necesario para superar y vencer al caos mismo. Tras una intensa lucha aparece el acto creativo que establece distinciones, que separa, que mide y que pone orden en el mundo (Ricoeur, 1967: 175). En suma, Bien y Mal constituyen dos naturalezas extrañas e inconmensurables, pero el Bien, de la misma forma que el orden social, se construye desde el horizonte del caos, se nutre de la materia del Mal. Ambos, por estas razones, siempre andan estrechándose la mano en una compleja y aparentemente extraña unidad. Y de ahí emerge fundamentalmente el horror, pues el caos y el desorden palpitan en una especie de interior-exterior de la naturaleza erigida por el orden social.

En la película El pianista, del director polaco Roman Polanski, se narra el calvario sufrido por Wladyslaw Szpilman, un brillante intérprete judío que milagrosamente escapa a la muerte durante la ocupación nazi de Polonia. El gueto de Varsovia constituye el escenario en el que las SS y la Gestapo alemanas infligen a los judíos polacos una continua y planificada cadena de actos absolutamente depravados. Las sucesivas vejaciones y humillaciones, el más absoluto desprecio a la dignidad humana, palidecen incluso ante el escenario de una muerte atroz y sin justificación. En una genial y sobrecogedora escena de la película, Roman Polanski nos muestra el horror y el estupor en estado puro. El pianista está escondido en una vivienda deshabitada. Una patrulla alemana llega hasta el portal del bloque de enfrente. La patrulla desciende del vehículo, entra en el portal y sube hasta el tercer o cuarto piso. Penetra en el interior de una vivienda. Una familia de judíos está congregada en torno a la mesa. Los policías alemanas les ordenan que se levanten. Wladyslaw Szpilman observa la escena. Uno de los comensales, sentado en una silla de ruedas, no se levanta. El policía, furioso, le ordena de nuevo que se ponga en pie. Pero permanece sentado. Entonces dos policías, cumpliendo instantáneamente una orden, levantan con gesto enérgico la silla de ruedas, se acercan a la ventana abierta y la lanzan al vacío de la calle. El sonido del cuerpo y de la silla al impactar con el empedrado rompe brutalmente el silencio de la noche. Wladyslaw Szpilman sigue mirando. Nadie dice nada.

El poder absoluto frente a la pura impotencia; la profunda repulsión de un acto abyecto que humilla y aniquila a un ser humano absolutamente inocente; y la incredulidad de la sorpre- 
sa, se muestran paradigmáticamente en este caso de horror. ¿Podía el espectador imaginar esa respuesta? ¿Somos capaces de comprender semejante acto de inhumanidad? ¿Cómo un ser humano llegar a cometer un acto así? ¿Es un ser humano o es un monstruo? Un ser humano capaz de cometer tales atrocidades, que excede los límites más extremos que distinguen entre la humanidad y la barbarie, ha de ser necesariamente un monstruo, una bestia, un animal. Por sus frutos los conoceréis. De ahí que la tesis de H. Arendt acerca de la «banalidad del mal», expuesta en su libro Eichmann in Jerusalem, causara tal impacto (Bernstein, 2002). Arendt no encontró en Eichmann ningún motivo extraordinario que le indujera a cometer tales crímenes contra la humanidad. Tan sólo, quizá, nos dice Arendt, un cierto interés por su medro personal: simplemente, dicho en términos coloquiales, nunca fue consciente de lo que estaba haciendo.

El horror siempre emerge de este límite paradójico y confuso en el que las aguas de la humanidad y de la inhumanidad parecen mezclarse. La figura del monstruo, que constituye la objetivación simbólica de nuestros sentimientos de horror, también se nutre de esta radical ambivalencia (Carroll, 1990). Es un ser ambiguo, ambivalente y mezclado, en parte humano y en parte animal, y por eso nos produce asco. Un ser extraño, ajeno a las codificaciones que establece la cultura. Procede de un mundo totalmente desconocido pero, como el extranjero, vive entre nosotros. Es al mismo tiempo indeseable e inevitable. Casi siempre demasiado grande o demasiado pequeño, pero siempre muy poderoso o siniestro, el monstruo no sólo nos desconcierta, sino que nos produce un intenso terror. Su mera presencia nos paraliza. El monstruo llega a nuestro mundo de la mano de la muerte, trae consigo la probabilidad de una aniquilación total. Representa el paradigma de la maldad, de lo demoníaco, de las fuerzas supra o infranaturales, de lo más perverso y malévolo, de todo aquello, en suma, que puede destruirnos o corrompernos desde dentro. El monstruo está con nosotros, vive con nosotros. El monstruo, en definitiva, participa de nuestra naturaleza, constituye una parte oscura, oculta, poderosa, siniestra, reprimida, brutal, destructiva, inhumana, repulsiva y abyecta de nuestro propio ser social.

El límite que señala el horror es un finisterre o última frontera cuyo contacto nos produce asco y pavor. Ante cualquier transgresión de la frontera, el orden social reacciona violentamente con el fin de repeler, expulsar, anular o aniquilar ese elemento que pone en riesgo el mantenimiento del orden social. En el estricto marco del yo individual, James Alexander sostiene (Alexander, 1977) que la función psíquica del horror consiste en incrementar hasta la máxima potencia la energía del sujeto con el fin de resistir ciertos impulsos disfuncionales del ego, o bien resistir tanto como sea posible ante los peligros más odiosos y repugnantes que amenacen al individuo desde el exterior. Podemos considerar al horror, por tanto, como una membrana muy sensible de la conciencia social que nos alerta de los flujos transfronterizos entre la humanidad y la barbarie, entre el orden y el caos social, entre la supervivencia y la 
aniquilación, entre el Bien y el Mal. Cuando algún elemento del exterior-interior de nuestro «mundo» logra atravesar la membrana se disparan las alarmas, se provoca una gran conmoción. En conjunto, todos los acontecimientos de horror sentidos por una determinada sociedad nos ofrecen una imagen bastante precisa de su contorno o frontera exterior. Una frontera que cambia de sociedad a sociedad y de época a época, pues cada orden social cuenta con una identidad propia. Dicho en palabras de Luhmann, establece su identidad frente a unas particulares diferenciaciones con respecto a su entorno. El esquema 2 se ha elaborado representando algunos hitos típicos de la conciencia social del horror presente en las sociedades avanzadas, hitos obtenidos mediante el análisis de una muestra representativa de horrores aparecidos en la prensa norteamericana en la última década del siglo xx.

El caso del senador republicano Trent Lott puede considerarse sintomático al respecto. Asistió a la fiesta de cumpleaños del centenario senador Strom Thurmond, conocido por su defensa del segregacionismo racial entre blancos y negros. Trent Lott declaró públicamente en la fiesta que le había votado para Presidente de los Estados Unidos, y que estaba orgulloso de él. Aunque desde la carrera presidencial de Thurmond habían pasado cincuenta años, los actuales comentarios de Lott parecían apuntar a la pervivencia de actitudes racistas entre algunos norteamericanos. El escándalo que produjeron estos leves comentarios fue tremendo y, en menos de una semana, la brillante carrera y la sólida posición política del senador Lott encontraron su fin. Tras las Navidades, el senador tuvo que dimitir como portavoz republicano del Senado. La indignación política fue intensa y abrumadora. La sociedad americana no podía tolerar que un político de su nivel hubiera despertado con sus comentarios el fantasma del racismo. El senador Lott había cruzado la frontera, y la conciencia social del horror, en la forma de un gran escándalo, se activó para expulsarle a él y a sus comentarios racistas. El espantoso crimen racista que, en 1998, había acabado con la vida de James Byrd, de 49 años y padre de tres hijos, estaba todavía muy vivo en la conciencia americana. Tres hombres le golpearon salvajemente, le encadenaron a la parte trasera de su furgoneta y arrastraron su cuerpo por un camino hasta causarle la muerte.

La función de señal que cumple el horror, así como la gran cantidad de energía que despliega la respuesta al mismo, sirven, como hemos dicho, al mantenimiento de un determinado orden social. Por ejemplo, de un orden social no racista que al menos pretende expulsar las manifestaciones más extremas del odio entre razas, así como las segregaciones más sangrantes, es decir, aquellas que pondrían en tela de juicio el principio de igualdad en la dignidad de negros y blancos. Pero el horror también sirve al cambio social y a la constitución de nuevos órdenes sociales. Las fronteras que jalonan los acontecimientos de horror son fronteras móviles, peculiares de cada sociedad y de cada época. No todas las sociedades se horrorizan ante los mismos hechos. Cada sociedad se construye mediante un elenco específico de acontecimientos de horror. «En el centro de las esperanzas y de la 
sensibilidad ética modernas - nos dice Susan Sontag - está la convicción de que la guerra, aunque inevitable, es una aberración» (Sontag, 2003: 87). Pero esto no siempre ha sido así, como por ejemplo nos muestra el carácter épico de los episodios bélicos relatados en la llíada, o las instrucciones que daba Leonardo da Vinci para que los artistas tuvieran el coraje de representar la guerra en todo su horror. Los horrores cambian, como también se muestra en el estupor provocado por la irrupción del SIDA en la década de los ochenta (Sontag, 2003), así como por su posterior integración en la conciencia colectiva de los países desarrollados, una vez que los fármacos aplicados en estos países lograron contener la enfermedad en el interior de límites tolerables.

Un caso actual y muy conocido, en el que pueden vislumbrarse con toda evidencia las relaciones entre el horror y el cambio social, es el maltrato femenino, la violencia que los hombres ejercen sobre las mujeres. Queda fuera de toda duda el hecho de que la violencia de género ha existido siempre, como también el hecho de que esta violencia se ha ejercido en condiciones de crueldad suficiente para causar intensos sentimientos de horror. Lo extraño, podríamos decir, es que, por ejemplo, en España la violencia de género se haya definido en términos de horror desde hace tan sólo un par de décadas. La sociedad española toleraba estos hechos. Pero la sociedad española comenzó a mostrar el horror de la violencia de género en las magulladuras del cuerpo de mujeres a las que hombres desalmados habían propinado palizas impresionantes; en la cara desfigurada de mujeres en las que algún novio o marido había vertido un producto químico; en el cuerpo sin vida, a veces cruelmente mutilado, de una mujer inocente a la que un hombre había decidido darle muerte.

Los espeluznantes sentimientos de horror aparecen cuando la sociedad decide construir un orden en el que no tenga cabida la comisión de estas barbaridades, por mucho que hasta hace poco idénticos hechos se observaran con indiferencia culpable o con cierta naturalidad. Horror significa tolerancia cero, y remoción de todos aquellos obstáculos que impidan la total expulsión de estos actos del orden social con el que nos identificamos. Ante el horror el cambio se impone. Y así ha sido, al menos, en España, en donde la lucha cultural, política, policial, institucional, punitiva y legal contra la violencia de género ha ido transformando sustantivamente las respuestas de nuestra sociedad. De ahora en adelante, la violencia de género constituye expresión de una naturaleza humana aborrecible que queda más allá, fuera, del límite más extremo que caracteriza a nuestra sociedad. Una vez que la sociedad española logre autoconstruirse mediante la autoobservación vinculada a la función de señal que aportan los sentimientos de horror evocados por la violencia de género, la notoriedad pública de estas barbaridades decrecerá. El horror habrá cumplido su papel en la construcción de un nuevo orden social, y sólo los más extremos actos de violencia de género conseguirán activar la membrana de la conciencia social para mantener viva la memoria del espanto y del horror. 


\section{SOCIEDADES CENTRÍPETAS Y SOCIEDADES CENTRÍFUGAS}

Tras el análisis de la tipología de los horrores contemporáneos, y de los múltiples casos de horror investigados cualitativamente, fueron emergiendo con claridad las conexiones existentes entre la cultura del horror y algunos rasgos básicos tanto de la estructura como de la dinámica de las sociedades avanzadas. Una vez finalizada la fase exploratoria de la investigación, en la que se obtuvieron un amplio conjunto de potenciales hipótesis explicativas, se llevó a cabo un análisis confirmatorio de las mismas. De este análisis emergieron cuatro teorías básicas y complementarias, de las que aquí expondremos tan sólo la que alude al cambio radical en el modo de legitimación, el cambio desde una sociedad centrípeta a una sociedad centrífuga. Las otras tres teorías tienen que ver con otros tantos rasgos fundamentales de las sociedades avanzadas. Primero, con el alto grado de fragmentación cultural y social que caracteriza a nuestras sociedades. Segundo, con el vertiginoso ritmo de cambio tecnológico, que altera todas nuestras condiciones sociales de operación e impide que vislumbremos con claridad el futuro. Y tercero, con el proceso de desarrollo de una especie de personalidad infantil, necesaria para alumbrar desde la ingenuidad y el temor un nuevo orden social que por ahora no controlamos. Cada una de estas teorías revela conexiones no paradójicas entre la cultura del horror y algún rasgo característico de nuestras sociedades en el proceso de transición que va desde un estado de «modernidad» hacia uno de «hipermodernidad» o «posmodernidad». Cada teoría pone de manifiesto, también, un tipo de negatividad o carencia fundamental que afecta a las sociedades posmodernas.

Según hemos anunciado, el estudio del horror ha revelado la existencia de dos modos o mecanismos alternativos mediante los que una determinada sociedad puede garantizar el mantenimiento del orden social. Según hemos señalado anteriormente, todo sistema social se constituye mediante una diferenciación de su entorno, lo que implica necesariamente algún tipo de clausura, cierre o condensación social, es decir, implica delimitar un área, campo o espacio social en el que rigen las operaciones propias del sistema. Pues bien, en las sociedades centrípetas, tal y como queda reflejado en el esquema 3, tanto la legitimidad como la motivación que sustentan el orden social se basan en el gran poder de atracción que ejerce un núcleo central de valores sobre las unidades componentes del sistema. La economía, la política o la cultura estarán orientadas específica, y positivamente, hacia el logro de esos valores. La legitimidad del orden social se mantiene en la medida que el sistema fomente y garantice una suficiente consecución de bienes. Asimismo, el sistema produce la motivación necesaria otorgando adecuadas recompensas, en términos de los bienes que conforman el núcleo central de valores, a los elementos del sistema que contribuyan mediante su esfuerzo al logro de esos valores. En una sociedad centrípeta, el espacio social se configura como un campo magnético orientado y atraído hacia un centro que opera como gran regulador del sistema. 
ESQUEMA 3.a

Sociedades centrípetas

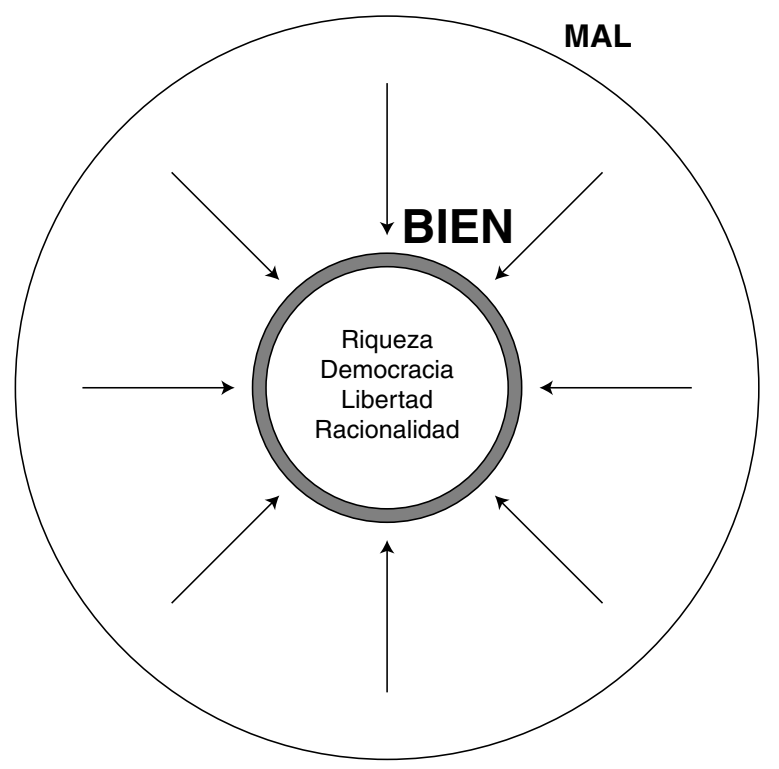

ESQUEMA 3.b

Sociedades centrífugas

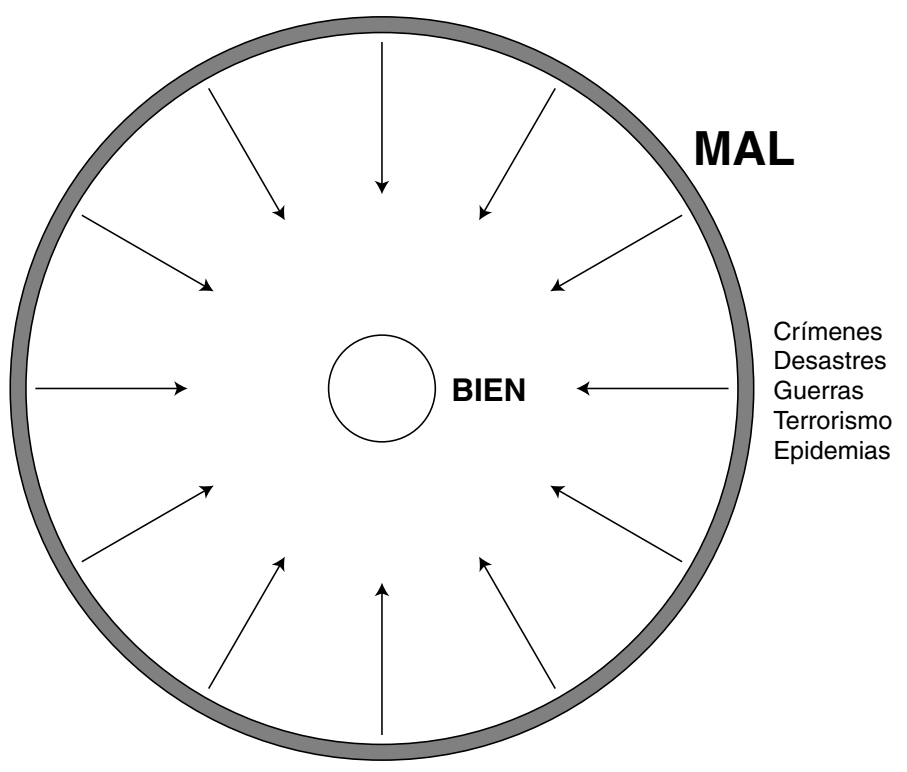


Pero ¿qué sucede cuando el poder de atracción que emana del cuerpo central de valores positivos que regula una determinada sociedad y época desaparece o pierde intensidad? Cuando esto sucede, es decir, cuando este cuerpo central de valores se debilita o pierde relevancia, mostrando su incapacidad para dotar de suficiente legitimidad o motivación al sistema, entonces las sociedades necesitan recurrir a otro mecanismo para mantener el orden social. En estos casos podremos hablar de sociedades o sistemas sociales centrífugos, pues debilitadas las fuerzas centrípetas que cerraban o condensaban el sistema mediante una potente atracción hacia el centro, las fuerzas centrífugas comienzan a manifestarse, poniendo en riesgo la identidad y la unidad del orden social. Los elementos del sistema, antes orientados hacia el centro por la fuerza de un potente atractor, se encuentran ahora en un campo de fuerzas debilitado en el que existe un mayor grado de libertad para orientarse aleatoria o incluso caóticamente, siguiendo la lógica de una especie de movimiento browniano, en muy distintas direcciones. En este estado, la probabilidad de que una parte de los elementos del sistema sobrepasen incluso los límites más extremos del orden social se incrementa. El pavor a las transgresiones flagrantes del orden social comienza a tomar cuerpo.

Una sociedad centrífuga es aquella que mantiene y construye el orden social remarcando sus límites externos y generando desde allí fuerzas de repulsión que impulsan hacia el interior a los elementos del sistema. Mientras que en las sociedades centrípetas la atracción al bien constituye el principal mecanismo regulador, en las centrífugas es la aversión al mal la que desempeña las funciones reguladoras del sistema. En este tipo de sociedades, tanto la transformación social como la agenda política se nutren con los propósitos de eliminar los aspectos más detestables de la realidad. En el juego político se ponderan más los errores que los aciertos, y más los escándalos que el cumplimiento de metas. Dado que no es posible definir el bien con contornos suficientemente precisos, y dado que debe admitirse un alto grado de tolerancia a la hora de respetar la adscripción a múltiples y diferentes valores positivos, los modelos ideales pierden intensidad. Al contrario, los modelos negativos, los anti-modelos, cobran cada vez mayor fuerza. El control de la negatividad se impone de una forma perentoria, y esto explica el hecho de que los medios de comunicación de masas dirijan la atención pública hacia el mal, esto es, hacia los desastres, la muerte, los crímenes más espantosos, los accidentes mortales, las epidemias, el terrorismo, la corrupción, la enfermedad, la inseguridad ciudadana o la guerra. Mientras que la identidad social de las sociedades centrípetas se funda en los sentimientos de orgullo que procura la consecución de logros, en las sociedades centrífugas la identidad se construye compartiendo colectivamente las emociones de horror.

Desde esta perspectiva, podemos considerar que las «sociedades modernas» constituyen un buen ejemplo de sociedades centrípetas. La sociedad moderna, desde sus mismos orí- 
genes, fue capaz de establecer un potente núcleo central de valores y realizaciones positivas suficientemente atrayentes como para mantener tanto la legitimidad del sistema como la adecuada motivación de sus miembros. La razón, el progreso, la ciencia, el bienestar material, la libertad individual, la democracia, los derechos civiles, el desarrollo económico y el incremento de la esperanza de vida formaban parte de ese núcleo central de valores. La modernidad se ha ido desarrollando mediante la realización progresiva e incesante de estos bienes. $Y$ esto explica el hecho de que el modo de legitimación centrípeto haya perdurado durante todo este tiempo. Las miradas de la modernidad siempre se dirigieron hacia ese próximo futuro en el que se producirían claros avances relacionados con el logro de sus valores.

La conocida teoría de la desviación social de Merton ilustra la naturaleza de una sociedad centrípeta. Merton nunca dudó de la capacidad de atracción que tenían los valores de la sociedad moderna. Tan sólo puso de manifiesto que la satisfacción de estos deseos, universalmente extendidos, se realiza en el marco de una estructura social desigualitaria en el acceso a los recursos. En suma, se trata de una teoría de la desviación basada en los sentimientos de frustración provocados por la incapacidad de alcanzar las metas mediante recursos o medios legítimos, lo que conduce en última instancia a tratar de conseguir por medios ilegítimos esos mismos objetivos. De otra parte, la teoría socioeconómica de Marx puede entenderse, también en el contexto de una sociedad centrípeta, como un denodado esfuerzo científico para que la sociedad industrial dejara de regularse, y estuviera exclusivamente orientada hacia el futuro, únicamente por el crecimiento económico y por el anhelo de incrementar la riqueza mediante un proceso feroz de acumulación de capital. Tan atrayentes debían resultar sus cantos de sirena que casi nadie, salvo Marx, prestó atención al reverso de este desarrollo, esto es, al gran sufrimiento humano con el que se estaba llevando a cabo esta profunda transformación social. Una sociedad centrípeta siempre dirige su mirada hacia la realización de sus valores positivos, pero apenas se preocupa de los esfuerzos y sacrificios naturalmente implicados en su logro.

Ahora bien, desde mediados del siglo xx, y sobre todo desde la década de los sesenta, una amplia gama de pensadores sociales, de filósofos y de artistas han venido señalando un cambio de rumbo cultural, una sustantiva modificación en la conciencia de los individuos de las sociedades modernas avanzadas. Adorno y Horkheimer, según hemos comentado, expresaron el cambio como la imposibilidad de definir el Absoluto positivo, sugiriendo una estrategia de transformación social centrada en la crítica de la negatividad. Por su parte, Habermas aludió a los problemas de legitimación del capitalismo tardío, y hubo de empeñarse en una defensa del proyecto ilustrado, que muchos creían ya agotado. Lyotard expresó el cambio de conciencia como una disposición de ánimo o estado de la mente caracterizado por la incredulidad frente a los grandes metarrelatos. Bell habló del fin de las 
ideologías. Inglehart, por su parte, demostró empíricamente la debilidad de los valores materialistas que habían caracterizado a la sociedad moderna. Y Norbert Elias, por citar un último ejemplo, expresó con su genialidad característica un argumento clave. En la época moderna el progreso económico constituía una ilusión, pero sin embargo ahora constituye tan sólo un hecho (Elias, 1993). Con ello aludía a la pérdida de capacidad motivadora de la que habían gozado los grandes objetivos y metas de la modernidad. En tanto ilusión, todas las metas alimentan el deseo; en tanto logro o hecho más o menos consumado, se muestran incapaces de motivar a nadie.

En general, muchos pensadores sociales, entre otros Giddens o Beck, avalan el factor causal subyacente al argumento de Elias, esto es, el hecho de que la modernidad muere cuando se enfrenta a las nuevas condiciones creadas por su propio éxito. Así, en la conciencia de los ciudadanos de las sociedades avanzadas podemos ver que la abundancia material alimenta las críticas al consumismo. La racionalidad impulsada por el proyecto moderno, según Habermas, fagocita el mundo de la vida, y de ahí la racionalidad emerge en el sentir de las gentes como puro dominio de la burocratización. La ciencia logra expandirse en la forma de un complejo científico-tecnológico tan poderoso que la Naturaleza acaba mostrando su debilidad y fragilidad. La secularización extrema fomenta el desencantamiento del mundo y un profundo vacío existencial. Los valores democráticos aparecen cada vez más como puro legalismo y formalismo. La libertad se transmuta en puro liberalismo ideológico o en mera libertad del consumidor. El individualismo, por citar un último ejemplo, se convierte en las sociedades avanzadas en un hiperindividualismo que corroe los lazos comunitarios y arrastra al ser hacia la soledad y el aislamiento sin sentido. En suma, las metas de la modernidad han dejado de ser ideales puros. Denzin sostiene que los ideales de la humanidad han desaparecido. Dicho en términos más precisos, estos ideales, cada vez más cuestionados, pierden eficacia a la hora de legitimar las sociedades y crear la necesaria motivación. Desde una conciencia ilusionada se ha pasado, en una primera fase, a una conciencia satisfecha y, en una fase ulterior, a un estado de desencanto y de sospecha respecto de los valores o dioses sagrados de la modernidad. Así que, a partir de la mitad del siglo, los modos de legitimación y de control social se han ido orientando cada vez más hacia el modelo típico de las sociedades centrífugas, y esto explicaría la utilización de los sentimientos de horror como medio de contener el orden social delimitando con claridad las fronteras externas y más extremas de su dominio.

En este sentido, Jean Baudrillard observa con perspicacia que el rechazo y la alergia visceral no sólo han sustituido a una negatividad y repugnancia fundada críticamente, sino que además alimentan los más emblemáticos fenómenos de nuestra época, a saber, las patologías virales, el terrorismo, las drogas o la delincuencia. Esta nueva actitud tiene más que ver con la compulsión por librarse de algo, que por el impulso a crear algo en 
absoluto. En la actualidad estamos mucho menos impulsados por motivaciones propias que por consideraciones de expulsión y de repulsión. Las grandes motivaciones o impulsos, con su positivo, electivo y atractivo poder, han desaparecido de la escena. Nuestros deseos se han debilitado; por contra, la poca disposición a, la repulsión de y el asco a son más sólidos que nunca. Y Baudrillard se pregunta si puede ser esto el principio del Mal en una nueva forma. Por otra parte, toda esta lógica del rechazo, de la alergia, del anticuerpo y de la repulsión no debe extrañar a nadie. En períodos de escasez, la absorción y la asimilación están a la orden del día. En períodos de abundancia, el rechazo y la expulsión constituyen las principales preocupaciones (Baudrillard, 1993: 71-74). El horror, compuesto de terror, asco y conmoción, figura como elemento esencial del ethos al que Baudrillard hace referencia, es decir, del modo característico en el que las sociedades centrífugas producen y mantienen el orden mediante un tipo especial de motivación y de legitimidad social.

Ahora bien, para comprender el modo en que los sentimientos colectivos de horror se insertan en la estructura y la dinámica social contemporánea debemos entender que estas emociones colectivas, escenificadas en el espacio de los medios de comunicación, están configuradas mediante la lógica del ritual. Un rito, según la teoría expuesta por Durkheim en Las formas elementales de la vida religiosa, es una institución que produce sociedad (Durkheim, 1993). Nosotros prensamos, por tanto, que los rituales mediáticos del horror producen sociedad (Bericat, 2002b), si bien es obvio que cada tipo de rito contribuye al mantenimiento de un determinado orden social.

Analizando los ritos sacrificiales de los intichiuma, Durkheim puso de manifiesto que todo ritual está compuesto esencialmente por dos actos, un acto de comunión y un acto de oblación o de entrega. Toda organización ritual constituye un proceso comunicativo y simbólico, orientado a la congregación de los miembros de un grupo, con el objeto de que éstos sacrifiquen su individualidad en aras de la realidad social que les trasciende. La eficacia del rito se logra cuando una determinada organización de actos consigue: primero, que los miembros del grupo dirijan su atención sobre un mismo punto o foco; segundo, que valoren del mismo modo algún elemento de la realidad social; y tercero, que los miembros del grupo experimenten simultáneamente un sentimiento común. El acto de comunión es un acto de comunicación cognitiva, valorativa y emotiva en el que comulgan todos los miembros del grupo. Y esta comunión establece las bases de un olvido y de una entrega del sí mismo, esto es, de los intereses particulares de cada uno, que funda el acto de sacrificio o de oblación. De este modo, según Durkheim, los ritos producen sociedad.

En este sentido, los acontecimientos de horror se muestran especialmente aptos par la producción ritual, pues contienen los tres mecanismos básicos mediante los que todo rito 
produce sociedad. En primer lugar, el vínculo que todo acontecimiento de horror mantiene con la muerte, una muerte nunca provocada en condiciones «naturales», sino una muerte espeluznante, sanguinaria, atroz, cruel o misteriosa, constituye un poderoso mecanismo para atraer la atención pública. En segundo lugar, dado que los acontecimientos horrorosos derivan de actos de una perversidad o maldad extrema, expresión de un poder amenazante que nos aterroriza, provocan fácilmente una idéntica valoración moral, un repudio compartido casi universalmente por toda la población. En tercer lugar, a tenor de que estos acontecimientos constituyen hechos absolutamente inesperados, que emergen bruscamente a la conciencia, gozan de la novedad y sorpresa característica de todo hecho noticiable, configurando así un potente sincronizador social que promueve una simultánea y unánime conmoción. Desde esta perspectiva, queda claro que el miedo es una emoción instrumental e individual, mientras que el horror es una emoción esencialmente social. En el horror, los individuos no temen exclusiva o directamente lo que les puede suceder o lo que les ha sucedido a ellos, sino lo que le ha sucedido o pueda suceder a cualquier miembro de la sociedad. Nos horroriza lo que le sucede a, o está pasando en, nuestra sociedad. El foco de atención ritual, tal y como señaló Durkheim, no es el individuo, sino la colectividad. Por este motivo, los rituales mediáticos del horror resultan ser tan aptos para marcar los límites del orden social. Cada ritual del horror es como una piedra que se añade a la muralla que delimita el contorno de la ciudad.

Las verdaderas noticias de horror constituyen siempre ritos sociales en los que la atención de la mirada se dirige hacia una transgresión flagrante del orden social. Las vejaciones y torturas llevadas a cabo por soldados americanos en la prisión iraquí de Abu Ghraib, en la que se priva a seres humanos de su mínima y sagrada dignidad, no sólo constituyen verdaderos sacrilegios, sino también pruebas evidentes del mal contenido en las supuestas «fuerzas del bien». Cuando la canguro inglesa es sorprendida en la grabación de un vídeo golpeando a los niños americanos que debía cuidar, nos encontramos frente a una inversión radical del orden social, frente a una absoluta ruptura de la confianza. Una mujer maltratada cruelmente por el hombre con el que convive niega de plano la realidad del amor basado en el respeto, en el cuidado y en la confianza que al menos la pareja debe procurar. El genocidio de Ruanda alerta de nuevo sobre el riesgo de las brutalidades colectivas, sobre el sin sentido de una violencia ejercida a golpe de machete con el más impensable y aterrador desprecio por la vida humana. Cuando Jon Venables y Robert Thompson, dos niños ingleses, secuestraron en un centro comercial y asesinaron posteriormente a James Bulger, otro niño, la conmoción alcanzó hasta el último rincón del planeta. Pero no es el miedo a que nos suceda esto a nosotros, o a nuestros hijos, lo que nos une en el espanto, sino la inversión de todos los valores, la inesperada, inimaginable y atroz mezcla de ingenuidad y de maldad. El niño, paradigma de la inocencia, se revela como un monstruo capaz de quitar la vida a un ser puramente inocente. 
En estos, así como en otros muchos acontecimientos de horror, lo determinante no es el número de muertes, sino las circunstancias que rodean a la muerte, la posibilidad de establecer un rito social en el que el foco de la atención pública se concentre en la maldad que proviene de un exterior que resulta ser, al fin y al cabo, un interior. El horror que hoy nos provocan los desastres naturales no deriva de la absoluta devastación que causan, sino de la vergüenza que nos produce comprobar nuestra impotencia frente a unas fuerzas que creíamos ya dominadas. En el horror evocado en el ataque de un perro peligroso a una persona inocente, también podemos encontrar el mismo tipo de impotencia y de responsabilidad. El hecho de que el mejor amigo del hombre destroce salvajemente una sola vida nos produce vergüenza, constituye un mal intolerable del que únicamente nosotros podemos considerarnos responsables. El horror ante la fuerza de virus y bacterias, pequeños seres vivos capaces de causar tremendas epidemias, también es síntoma de la debilidad humana. Y lo es también la realidad de un simple embotellamiento, que muestra las limitaciones de un éxito tecnológico, ideado para salvar con rapidez distancias físicas, cuando toda la potencia del vehículo se aplica, paradójicamente, para alcanzar la velocidad cero. Somos la causa del mal, y somos nosotros quienes debemos transformar la naturaleza humana y social para evitar el espectáculo del horror. Nuestras miradas y nuestros esfuerzos confluyen ahora en una misma dirección. La vida adquiere al menos un mínimo, aunque negativo, sentido común.

En una sociedad centrífuga no sabemos en qué puede consistir el bien, pero sabemos en qué consiste el mal. Y esta claridad moral se nos presenta únicamente, en la actualidad, cuando nuestro foco de atención se concentra en el horror. Por citar un último ejemplo, aparentemente trivial pero sintomático, podemos referirnos a la elevada audiencia que tienen los programas televisivos basados en la difusión pública de las truculentas historias de los llamados falsos famosos. Estos famosos, desde nuestra perspectiva, componen en conjunto una singular corte del horror. La lógica de estos programas consiste, como todo el mundo sabe, no tanto en mostrar modelos personales ideales, personajes valiosos o héroes, sino, muy al contrario, en mostrar anti-héroes, personas ridículas que parecen representar a la perfección la quintaesencia del anti-valor. Todos estamos de acuerdo en que estos personajes son un horror y, sin embargo, seguimos mirando. Nadie alberga ninguna duda moral acerca de que son un horror, y quizá por ello son un tema constante de nuestra conversación. El hecho definitivo es que casi todos podemos vernos reflejados colectivamente en el espejo de este escenario como personas normales y morales, es decir, como personas que habitamos en el interior de los límites marcados por nuestro orden social. Lo que la gente entiende menos es por qué estos personajes tienen tanta fama y cobran tanto dinero por salir a escena. Ahora bien, desde la teoría de las sociedades centrífugas, y desde la perspectiva del horror, el fenómeno en cuestión adquiere un nuevo sentido. Estos personajes son empleados del orden social que realizan su trabajo como marionetas de un 
tipo especial de rituales mediáticos del horror. Ya que no somos capaces de ponernos de acuerdo para valorar y admirar modelos personales positivos o ideales, al menos nos ponemos de acuerdo para definir y despreciar modelos negativos y repelentes. Éste es precisamente el mecanismo con el que las sociedades centrífugas tratan de mantener un cierto sentido de orden y de cohesión social.

\section{CONSIDERACIÓN FINAL}

En esta investigación hemos tratado de explicar sociológicamente la cultura del horror que caracteriza a las sociedades avanzadas en su proceso de transición desde la modernidad hacia la posmodernidad. Creemos haber recorrido un largo viaje desde aquellas primeras impresiones hasta la formalización final de las teorías que, a nuestro juicio, explican este nuevo clima emocional. Sin embargo, explicar o comprender un determinado fenómeno social nunca implica una justificación del mismo. En contra de uno de los más íntimos pensamientos de Hegel, no estamos dispuestos a aceptar que todo lo real sea racional. Así como tampoco estamos dispuestos a aceptar esta cultura del horror por el mero hecho de que hayamos probado su existencia, e incluso su necesidad en las actuales circunstancias. Los seres humanos, como los científicos sociales, nunca observamos la realidad con el fin de legitimarla, sino con la profunda intención de evaluarla y, en su caso, transformarla. La cultura del horror es, según hemos visto, uno de los más preclaros síntomas de nuestro tiempo. De ahí la relevancia de su análisis. Estudiando el horror, siendo conscientes del horror, hemos tomado conciencia de nuestra situación. Analizando la cultura del horror hemos vislumbrado con mucha mayor claridad una imagen de la sociedad y del individuo contemporáneos. Pero la imagen de un ser humano atemorizado, de una individualidad infantil e inmadura, de una persona que ha perdido la ilusión y no sabe lo que quiere, nos horroriza.

George H. Mead, ya en 1918, en el artículo titulado «The Psychology of Punitive Justice», publicado en la revista The American Journal of Sociology, alertaba sobre las indeseables consecuencias de los modos de obtener cohesión social, basados en lo que él denominaba «actitud hostil». El artículo debe entenderse como el compendio de una disputa virtual protagonizada por E. Durkheim y G. H. Mead. El tema a debate son las consecuencias sociales del crimen, y las consecuencias sociales del modo en que la sociedad reacciona ante él. E. Durkheim sostuvo en diversas ocasiones que el crimen, y la respuesta social que provocaba, constituía una situación especialmente idónea para el logro de cohesión social. Mead, aun admitiendo los efectos que sobre la cohesión y la solidaridad tiene esta actitud hostil, subraya en su análisis dos consecuencias perversas importantes. La primera es que en este tipo de solidaridad emocional queda suprimida la individualidad. La segunda es que en este modo de reacción social no se afirman las funciones positivas de los va- 
lores que defendemos. Para Mead, una reconstrucción social solamente puede realizarse desde estos dos supuestos, es decir, desde una individualidad no asfixiada por el vendaval de las emociones colectivas, y desde una clara exposición de las funciones sociales positivas que han de cumplir nuestros valores.

La relación de estos argumentos con la cultura del horror descrita en esta investigación resulta suficientemente obvia, pues en los sentimientos colectivos de horror están presentes todos los rasgos de la actitud hostil típica de la justicia punitiva. Y si la cultura del horror, según nuestra interpretación, expresa el clima del fin de una época y, por tanto, señala la necesidad de una profunda reconstrucción social, los sentimientos del horror, subrayando tan sólo aquello que es intolerable, son incapaces de promover la necesaria discusión colectiva en términos de las funciones y de los valores sociales positivos que debemos instituir en la nueva sociedad. Hoy el horror puede resultarnos muy necesario, casi imprescindible, pero desde el horror ni podemos afrontar el presente ni podremos construir el futuro. Necesitamos saber lo que queremos, y hacia dónde queremos caminar juntos. Necesitamos, en suma, nuevas fórmulas positivas de solidaridad social.

\section{BIBLIOGRAFÍA}

ADORNO, Th. W. (1975): Dialéctica negativa, Madrid, Taurus.

— (2004): Mínima moralia. Reflexiones desde la vida dañada, Madrid, Akal.

ALEXANDER, J. (1977): “On The Affect of Horror», en Ch. W. Socarides (ed.), The World of Emotions, Nueva York, International Universities Press.

ALTHEIDE, D. L. (2002): Creating Fear. News and the Construction of Crisis, Nueva York, Aldine de Gruyter.

ALTHEIDE, D. L., y MICHALOWSKI, R. S. (1999): «Fear in the News. A discourse of Control», en The Sociological Quarterly, vol. 40, n. ${ }^{\circ}$ 3, pp. 475-503.

BAUDRILLARD, J. (1993): Evil. Essays on Extreme Phenomena, Nueva York, Verso Books.

BERICAT ALASTUEY, E. (2000): «La sociología de la emoción y la emoción en la sociología», en Papers. Revista de Sociología, n. ${ }^{\circ} 62$, pp. 145-176.

- (2002a): «¿Sienten las sociedades? Emociones individuales, sociales y colectivas», en P. Fernández y N. Ramos (coords.), Corazones inteligentes, Barcelona, Kairós, pp. 121-144.

- (2002b): «Rituales mediáticos, emociones colectivas y orden social», en VV.AA., La sociedad: Teoría e Investigación empírica. Libro homenaje a José Jiménez Blanco, Madrid, Centro de Investigaciones Sociológicas (CIS), pp. 765-782.

- (2003): «Fragmentos de la realidad social posmoderna», en Revista Española de Investigaciones Sociológicas (REIS), n. ${ }^{\circ} 102$, pp. 9-46.

BERNSTEIN, R. J. (2002): Radical Evil. A Philosophical Interrogation, Cambridge, Polity Press. 
BOZAL, V. (2004): El tiempo del estupor, Madrid, Siruela.

BUBER, M. (1996): I and Thou, Nueva York, Simon \& Schuster.

— (1997): Good and Evil, New Jersey, Prentice Hall.

CARROLL, N. (1990): The Philosophy of Horror or Paradoxes of the Heart, Nueva York, Routledge.

DAYAN, D., y KATZ, E. (1988): «Articulating consensus: the ritual and rhetoric of media events», en J. C. Alexander (ed.), Durkheimian Sociology: Cultural Studies, Nueva York, Cambridge University Press.

DOUGLAS, M. (1994): Risk and blame, Londres, Routledge.

- (2002): Purity and Danger. An Analysis of Concepts of Pollution and Taboo, Nueva York, Routledge.

DURKHEIM, E. (1993): Las formas elementales de la vida religiosa, Madrid, Alianza.

ELIAS, N. (1993): El proceso de la Civilización. Investigaciones sociogenéticas y psicogenéticas, Madrid, Fondo de cultura Económica.

ERIKSON, K. T. (1968): Wayward Puritans: A Study in the Sociology of Deviance, Pearson, Allyn \& Bacon.

FREUD, S. (1926): «Inhibitions, Symptoms, and Anxiety», en J. Strachey (ed.), Standard Edition, vol. 20, Londres, Hogarth Press, pp. 77-176.

FUREDI, F. (1997): Culture of Fear. Risk-Taking and the Morality of Low Expectation, Londres, Cassell.

GARFINKEL, H. (1963): "A Conception of, and Experiments with, "Trust" as condition of Stable Concerted Actions", en O. J. Harvey (ed.), Motivation and social Interaction, Nueva York, The Ronald Press Company, pp. 187-238.

GIL CALVO, E. (2003): El miedo es el mensaje. Riesgo, incertidumbre y medios de comunicación, Madrid, Alianza.

GLASSNER, B. (1999): The culture of fear. Why Americans are afraid of the Wrong Things, Nueva York, Basic Books.

HOBBES, Th. (1994): Leviathan, Indianapolis, Hackett Publishing.

HOCHSCHILD, A. R. (1983): The Managed Heart. Commercialization of Human Feeling, Berkeley, University of California Press.

HORKHEIMER, M. (1973): Crítica de la razón instrumental, Buenos Aires, Editorial Sur.

HUME, D. (1981): Tratado de la naturaleza humana, Madrid, Editora Nacional.

KEMPER, Th. (1978): A Social Interactional Theory of Emotions, Nueva York, John Willey \& Sons.

KÖVECSES, Z. (1990): Emotion Concepts, Nueva York, Springer-Verlag.

KRISTEVA, J. (1982): Powers of Horror. An Essay on Abjection, Nueva York, Columbia University Press.

LAMONT, M., y MOLNÁR, V. (2002): "The Study of Boundaries in The Social Sciences», en Annual Reviews of Sociology, n. ${ }^{\circ} 28, \mathrm{pp}, 167-195$.

LOVECRAFT, H. P. (2001): «The Dunwich Horror», en H. P. Lovecraft, The Thing on the Doorstep and Other Weird Stories, Nueva York, Penguin Books.

LUCKMANN, Th. (2000): «Comunicación moral e instituciones intermedias en las sociedades modernas», en Papers, n. ${ }^{\circ} 62$, pp. 83-96. 


\section{EDUARDO BERICAT ALASTUEY}

LUHMANN, N. (1995): Social Systems, Stanford, Stanford University Press.

LULL, J., y HINERMAN, S. (eds.) (1997): Media Scandals. Morality and Desire in the Popular Culture Marketplace, Nueva York, Columbia University Press.

MEAD, G. H. (1918): «The Psychology of Punitive Justice», en The American Journal of Sociology, vol. XXIII, n. ${ }^{\circ}$, pp. 557-602.

MILLER, W. I. (1997): The Anatomy of Disgust, Cambridge, Harvard University Press.

PARSONS, T. (1982): El sistema social, Madrid, Alianza.

RICOEUR, P. (1969): The Symbolism of Evil, Boston, Beacon Press.

RIVERA, J. de (1992): «Emotional Climate: Social Structure and Emotional Dynamics», en International Review of Studies on Emotion, editado por K. T. Strongman, vol. 2, pp. 197-218.

RODRÍGUEZ IBÁÑEZ, J. E. (1998): ¿Un nuevo malestar en la cultura? Variaciones sobre la crisis de la modernidad, Madrid, Centro de Investigaciones Sociológicas (CIS).

ROSZAK, Th. (1981): El nacimiento de una contracultura, Barcelona, Kairós.

RUSSELL, S. A. (2002): Revisiting Stephen King. A Critical Companion, Westport, Greenwood Press.

SCHEFF, Th. J. (1990): Microsociology. Discourse, Emotion and Social Structure, Chicago, The University of Chicago Press.

SMITH, A. (1997): La teoría de los sentimientos morales, Madrid, Alianza.

SONTAG, S. (2003): Ante el dolor de los demás, Madrid, Santillana.

TAYLOR, Ch. (2002): «The Cultural Face of Terror in the Rwandan Genocide of 1994», en A. L. Hinton (ed.), Annihilating difference. The Anthropology of Genocide, Berkeley, University of California Press.

TRÍAS, E. (2005): La política y su sombra, Barcelona, Anagrama.

WEBER, M. (1979): Economía y Sociedad, México, FCE. 
This article sets out the main results obtained from a research study carried out for the purpose of analysing the role that collective emotions play in maintaining social order. In specific terms, it attempts to explain the fact that the most important items of news that appear in the media are news of horror, in other words, news in which death always appears in the foreground. The news programmes of the media express and encourage the culture of horror that is characteristic of our advanced societies. However, in order to understand this culture, we must first establish the emotional nature of horror and also establish a sociological definition of this feeling. Horror is a complex emotion made up of feelings of terror, disgust and shock. Sociologically speaking, horror can be understood as «the emotion through which a social order indicates its outermost limits». The study concludes showing that there are two alternative ways of maintaining order and cohesion within the bosom of a social system. The first method of legitimation, which is characteristic of centripetal societies, works through the great power of attraction it exerts over the social field of a central nucleus of positive social values. The second, which is characteristic of centrifugal societies, works through the great power of repulsion exerted by flagrant transgressions of moral order over the social field. The typical method in which centrifugal societies regulate social order explains the culture of horror that is characteristic of our advanced societies.

Key words: Sociology of the Emotions, Post-modernity, Fear, Horror, Terror, Disgust, Shock, Emotional Climates, Social Order, Social Cohesion, Legitimacy, Culture, Public Opinion. 